\title{
Assessment of a combination of three heat sources for heat pumps to supply district heating
}

Pieper, Henrik; Ommen, Torben; Elmegaard, Brian; Markussen, Wiebke Brix

Published in:

Energy

Link to article, DOI:

10.1016/j.energy.2019.03.165

Publication date:

2019

Document Version

Peer reviewed version

Link back to DTU Orbit

Citation (APA):

Pieper, H., Ommen, T., Elmegaard, B., \& Markussen, W. B. (2019). Assessment of a combination of three heat sources for heat pumps to supply district heating. Energy, 176, 156-170.

https://doi.org/10.1016/j.energy.2019.03.165

\section{General rights}

Copyright and moral rights for the publications made accessible in the public portal are retained by the authors and/or other copyright owners and it is a condition of accessing publications that users recognise and abide by the legal requirements associated with these rights.

- Users may download and print one copy of any publication from the public portal for the purpose of private study or research.

- You may not further distribute the material or use it for any profit-making activity or commercial gain

- You may freely distribute the URL identifying the publication in the public portal 


\title{
Assessment of a combination of three heat sources for heat pumps to supply district heating
}

\author{
Henrik Pieper ${ }^{a, *}$, Torben Ommen $^{a}$, Brian Elmegaard ${ }^{a}$, Wiebke Brix Markussen ${ }^{a}$ \\ ${ }^{a}$ Technical University of Denmark, Department of Mechanical Engineering, Nils Koppels Allé Building 403, 2800 \\ Kgs. Lyngby, Denmark
}

\begin{abstract}
This paper reports a study on how hourly temperature variations of different heat sources influence the seasonal coefficient of performance (SCOP) of heat pumps (HPs) when supplying district heating. The considered heat sources were: groundwater, seawater, air and a combination of the three. The system included HPs, an electric peak load boiler and short-term storage. Linear programming was used to minimize annual electricity consumption of the system. This process also determined the optimum capacities of the HPs using different heat sources. The study was based on data for the area of Copenhagen, Denmark.

The results showed that the SCOP of seawater and air HPs, considering heat demand variations, was $11 \%$ and $15 \%$ lower, respectively, than their arithmetic mean performances. For a combination of heat sources, the optimum proportions of HP capacities were: $63 \%, 14 \%$ and $23 \%$ for the groundwater, seawater and air HP, respectively. The SCOP of such system was found to be $3 \%, 6 \%$ and $11 \%$ greater than the SCOP of a system using the heat sources individually. The results indicate that a maximum system performance may be achieved for HPs based on a combination of different heat sources.
\end{abstract}

Keywords: District heating, Energy planning, Heat pumps, Linear programming, Low-temperature heat sources

\section{Introduction}

District heating $(\mathrm{DH})$ dominates the heat supply in Denmark and supplies heating to $64 \%$ of residential buildings, of which $51 \%$ is based on renewable energy sources (RES) [1]. Denmark's goal is to become independent of fossil fuels by 2050 [2]. In order to become $100 \%$ sustainable, DH networks will have to undergo major changes. Currently, DH supply temperatures during winter periods in Denmark vary between $70{ }^{\circ} \mathrm{C}$ and $90{ }^{\circ} \mathrm{C}$ [3]. Lund et al. [4] defined a fourth generation of district heating (4GDH) with supply temperatures ranging from $30{ }^{\circ} \mathrm{C}$ to $70{ }^{\circ} \mathrm{C}$. They argued that a reduced DH supply temperature has several advantages. Among others, heat losses in the grid are reduced and low-temperature heat sources can be exploited, either directly or by using a heat pump (HP).

Ommen and Elmegaard [5] and Elmegaard et al. [6] showed that the benefits of having low DH supply temperatures differ depending on whether domestic hot water (DHW) is supplied directly or if a temperature boost is required, e.g. by using a HP. These findings were supported by Lund et al. [7] who investigated three different low-temperature district heating (LTDH) concepts for near term and long term future energy scenarios. The results of their socioeconomic analysis showed that the LTDH concept with supply temperature of $55{ }^{\circ} \mathrm{C}$ entails the lowest total energy system costs and the lowest total primary energy supply compared to the other two concepts with lower supply temperatures.

Lund et al. [8] and Connolly et al. [9] defined Smart Energy Systems as "an approach in which smart electricity, thermal and gas grids are combined with storage technologies and coordinated to identify synergies between them in order to achieve an optimal solution for each individual sector as well as for the overall energy system". One of these synergies is to use electricity for heat production by a HP or an electric boiler. This can lead to the use of existing thermal storage capacity instead of installing electrical storage, which is cheaper and more

*Corresponding author

Email addresses: henpie@mek.dtu.dk (Henrik Pieper), tsom@mek.dtu.dk (Torben Ommen), wb@mek.dtu.dk (Wiebke Brix Markussen), be@mek.dtu.dk (Brian Elmegaard) 


\begin{tabular}{|c|c|c|c|}
\hline \multicolumn{4}{|c|}{ Nomenclature } \\
\hline$c_{\mathrm{p}}$ & Specific heat, $\mathrm{kJ} / \mathrm{kg} / \mathrm{K}$ & level & Storage level \\
\hline COP & Coefficient of performance, - & Im & Logarithmic mean \\
\hline$f_{\text {loss }}$ & Storage heat loss factor & loss & Heat loss \\
\hline FLH & Full load hours, h & $\min$ & minimum \\
\hline$\dot{m}$ & Mass flow rate, $\mathrm{kg} / \mathrm{s}$ & $N$ & Number of hours a year \\
\hline$P$ & Electricity, MWh & $n$ & Index for current hour \\
\hline SCOP & Seasonal coefficient of performance, - & 0 & Outlet \\
\hline$T$ & Temperature, $\mathrm{K}$ or ${ }^{\circ} \mathrm{C}$ & Peak, el. & Electric peak boiler \\
\hline $\bar{T}$ & Mean temperature, $\mathrm{K}$ & pipe & DH pipe network \\
\hline$Q$ & Heat production/consumption, $\mathrm{MWh} / \mathrm{h}$ & return & Return line \\
\hline$\dot{Q}_{d}$ & Design heat capacity/heat flow rate, MW & sea & Seawater-source HP \\
\hline$\dot{V}$ & Volume flow rate, $\mathrm{m}^{3} / \mathrm{s}$ & $\mathrm{SH}$ & Space heating \\
\hline \multirow[t]{2}{*}{$\dot{W}$} & Power, MW & sink & Heat sink \\
\hline & & source & Heat source \\
\hline \multicolumn{2}{|c|}{ Greek symbols } & Sum & summarised \\
\hline$\eta$ & Efficiency, - & supply & Supply line \\
\hline \multirow[t]{2}{*}{$\rho$} & Density, $\mathrm{kg} / \mathrm{m}^{3}$ & st & Heat storage \\
\hline & & Sys & System \\
\hline Subscripts & & tot & Total \\
\hline 10 & Seawater at $10 \mathrm{~m}$ depth & $U$ & Maximum number of different production units \\
\hline 2015 & Year 2015 & $u$ & Index for different type of production unit \\
\hline 2017 & Year 2017 & & \\
\hline air & Air-source HP & \multicolumn{2}{|c|}{ Abbreviations } \\
\hline avg & Average & $4 \mathrm{GDH}$ & Fourth generation of district heating \\
\hline$c$ & Cold side & $\mathrm{CHP}$ & Combined heat and power \\
\hline char & charging & $\operatorname{COP}(s)$ & Coefficient(s) of performance \\
\hline$d$ & Design conditions & $\mathrm{DH}$ & District heating \\
\hline daily & Daily & $\mathrm{DHW}$ & Domestic hot water \\
\hline demand & Heat demand & DRY & Danish Design Reference Year \\
\hline dis & discharging & EES & Engineering Equation Solver \\
\hline DRY & Danish Design Reference Year & FLH & Full load hours \\
\hline fit & Fit function & GAMS & Generic Algebraic Modelling System \\
\hline Gauss & Gauss distribution & GW & Groundwater \\
\hline GW & Groundwater-source HP & $H P(s)$ & Heat pump(s) \\
\hline$h$ & Hot side & LTDH & Low-temperature district heating \\
\hline HP & Heat pump & RES & Renewable energy sources \\
\hline$i$ & Inlet & SCOP & Seasonal coefficient of performance \\
\hline J & Maximum number of different heat sources & Sea & Seawater \\
\hline$j$ & Index for different type of heat source & SH & Space heating \\
\hline$L$ & Lorenz & & \\
\hline
\end{tabular}

efficient. Using electricity for heating may also help in balancing power and providing services to the electrical grid. Thus, HPs are a relevant technology for Smart Energy Systems.

Several studies have been made in order to investigate the potential of integrating HPs in energy systems for an efficient integration of large amounts of RES. Lund et al. [10] based their research on two energy system analysis tools, EnergyPLAN [11] and MODEST [12], with the focus on the socioeconomic potential of integrating largescale HPs in Denmark. One of their assumptions was a constant coefficient of performance (COP) of HPs. 
Hedegaard and Balyk [13] presented an energy system investment model that included flexible operation of individual HPs and thermal energy storages in order to efficiently integrate a large share of wind energy of $60 \%$ into a possible Danish Energy System of 2030. They assumed the COP of HPs to be the yearly average. Rinne and Syri [14] conducted a consequential life cycle assessment study of HPs and combined heat and power (CHP) production in Finland to calculate $\mathrm{CO}_{2}$ emission factors. They pointed out the importance of seasonal variations in the electricity price, consumption data and CHP production. Therefore, they included hourly variations of these parameters. However, the COP for the HPs was assumed to be constant. A constant COP for HPs was also assumed in other studies that looked at different ways of integrating more RES at national or city level, such as in Trondheim, Norway [15], in Geneva, Switzerland [16], in Belgium [17], in Finland [18] or in Denmark [19-21]. The COP of a HP, however, may vary during the year depending on the heat source and heat sink temperatures. For instance, air, seawater, lakes and rivers are all influenced by ambient conditions. In the same time, $\mathrm{DH}$ forward temperatures are reduced in warmer periods with lower heat demands in order to reduce heat losses in the network. This is why it may be important for energy planning and energy system analysis to calculate the COP based on a daily or even hourly resolution for an efficient integration of HPs to balance intermittent electricity production from RES.

Such detailed calculation was performed as part of the study conducted by Lund et al. [7]. They determined hourly values of COP based on a Lorenz cycle with constant Lorenz efficiency over the year for HPs using seawater. A Lorenz cycle takes into account the inlet and outlet temperatures of the heat source and the heat sink of a HP. For other heat sources, they assumed the seawater temperature profile, but added a constant temperature increase. They focused on the analysis of LTDH concepts at different DH network temperatures, as mentioned above, and not on a detailed analysis of which heat source is the most suitable to supply heat to a DH network by HPs.

$\emptyset$ stergaard and Andersen [22] also conducted a study using hourly calculations of COP assuming a Lorenz cycle with constant efficiency. They used the energy system simulation model energyPRO [23] to investigate the optimal use of central HPs and decentral booster HPs for a future electrified LTDH system based on RES. The focus of the study was on finding the optimal DH temperatures to increase performance of the HPs and to reduce heat losses. They did not concentrate on heat sources used for the HPs.

Holmgren [24] investigated how waste heat can be utilized in DH based on the DH network in Gothenburg, Sweden. The production units consisted of a number of heat only boilers using different kinds of fuel, CHP plants based on waste and natural gas and large-scale HPs. The author used the energy system analysis tool MODEST [12] for the optimization of the operation of the production units for six different scenarios. It was shown that the heat supply from the HPs as well as the system costs depended on the scenario. Information about the COP of the HPs was not stated.

Heat sources may have very different and varying temperature levels, and may be limited in capacity or availability. A few studies have investigated different heat sources used for HPs.

Berntsson [25] analysed the most common heat sources for HPs used in Sweden for both, small systems to heat individual buildings and for large systems connected to $\mathrm{DH}$. He focused on the analysis of key parameters of heat sources such as annual temperature variation, absolute temperature level, temperature glide and availability. Furthermore, economic and environmental aspects were investigated. The main heat sources for small systems were: ambient air, exhaust air, lake or river water, soil and rock. For large systems, mainly lake water and cleaned sewage water was used. The two main conclusions were that HPs can contribute to the reduction in $\mathrm{CO}_{2}$ emissions and that the reduction in $\mathrm{CO}_{2}$ emissions is larger for water-based HPs than for air-based HPs, in particular for large systems. The main reasons are a combination of difference in COP, annual operating time and investment costs. 
David et al. [26] reviewed and analysed existing large-scale HPs in DH systems in Europe with an installed thermal capacity above $1 \mathrm{MW}$. Their findings show that by 2017, 149 large-scale HPs had been installed, with a total capacity of $1580 \mathrm{MW}$. These HPs differed in size, heat source, supply temperature, refrigerant, operating mode and COP. They identified seven different heat sources, among which sewage water, ambient water (seawater, lakes and rivers), industrial waste heat and geothermal water were the most commonly used. They stated that sewage water is the heat source with the most advantages in terms of temperature, long-term stability and shortest distance to urban areas, although using ambient water as heat source may result in good performance, too.

Lund and Persson [27] identified the most suitable heat sources for HPs, which could be introduced in DH networks in Denmark. The outcome of the study was a map of Denmark showing the heating capacity of available heat sources and heat demands. It was noted that heat sources were distributed all over Denmark, but that their heating capacity was not proportional to the local heat demand. They concluded that groundwater had the highest potential to serve as a heat source for HPs in Denmark, due to its geographical distribution and potential heat capacity.

These two previous studies did not investigate how the available heat sources could be integrated efficiently during the year using HPs to supply DH. In addition, the literature review showed that in energy system analysis the COP of a HP is often assumed to be constant and the heat sources that may be used were not analysed in detail.

The current study was based on the Danish capital region of Copenhagen. The city council agreed in 2012 on a climate plan to become the first $\mathrm{CO}_{2}$ neutral capital in the World by 2025 [28]. In Copenhagen, DH supplies $98 \%$ of the heat demand [29]. In 2015, $53 \%$ of the supplied heat was $\mathrm{CO}_{2}$ neutral [30]. This indicated that it would be necessary to transform the DH network even further. In 2014, the three major utility companies of Copenhagen reported in the Heating Plan of Greater Copenhagen that 300 MW of installed HP capacity may be required by 2035 to supply sustainable and feasible cheap DH without depending on biomass only [31].

The possibilities of integrating large-scale HPs into DH for the Greater Copenhagen area were analysed by Bach et al. [32] from a technical and private-economic perspective using the energy system model Balmorel [33]. For their analysis, they considered: sewage water, drinking water and seawater with certain capacity limits either from the heat source or from the heat demand. The COP was calculated at a seasonal level for one week in each month in order to investigate how its change would influence the results. The present study is going one step further by calculating hourly values of COP for the entire year. Furthermore, the literature survey showed that none of the studies investigated potential benefits of using different heat sources together within one energy system to supply DH by HPs.

The choice of the heat source may entail a significant impact on the system performance. Each considered heat source was characterized by different temperature profiles and other properties that might vary. This motivated an investigation on how these variations result in changes in COP. Combining a number of HPs with different heat sources might lead to an overall improvement in system performance, because of changing characteristics of the heat sources during the year. Thereby, the heat source resulting in the highest HP performance may always be used at a given time. This may be an advantage compared to the use of a single heat source and will be investigated in detail in the current study. Such improvement may be seen as a theoretical maximum. Therefore, the purpose of the present study was to

- Compare the overall system performance considering seasonal and hourly variations in COP and heat demand or assuming the use of a constant COP during the year.

- Investigate how the variation in the COP on an hourly basis influences the choice of using different heat sources for HPs to supply heat to a DH network. 
- Analyse how a given heat demand and varying $\mathrm{DH}$ supply temperatures affect the seasonal performance of HPs based on different heat sources.

- Investigate the potential benefit of using a combination of heat sources for HPs within one energy system compared to the use of a single heat source.

- Identify the optimal proportion of different heat sources used by HPs to supply heat to a DH network.

\section{Methods}

A model was developed in the Generic Algebraic Modelling System (GAMS, version 24.8.3) [34] to investigate which heat source or combination of them is best suited for HPs supplying $\mathrm{DH}$. The model was developed with the intention of using it during an early planning stage of a new $\mathrm{DH}$ area when details about required production capacity are unknown and no decision about the heat source has been made. Linear programming was used to carry out an annual optimization on an hourly basis to minimize total electricity consumption.

Seawater, groundwater and air were considered as heat sources for HPs, and an electric peak load unit and shortterm storage were included in the model. Investments and auxiliary electricity consumption were not included. The calculations of COP were based on a Lorenz cycle as it was done in [7,22]. A Lorenz cycle may be seen as a simplified way to calculate the COP of a HP without modelling it in detail, but it allows the results to be independent of specific component and system parameters.

\subsection{System description}

Four different cases were defined in order to compare the three heat sources with each other as shown in Fig. 1. The case in which HPs were based on a combination of heat sources, hereafter referred to as the multiple heat source case, was compared to three reference cases, each using only one of the three heat sources. The reference cases were: the groundwater case, the seawater case and the air case using these heat sources only individually. The total HP capacity for all four cases was the same, as illustrated using example capacities in Fig. 1. The multiple heat source case represents the theoretical maximum in system performance that may be achieved when combining HPs with different heat sources by exploiting them at the most beneficial times.
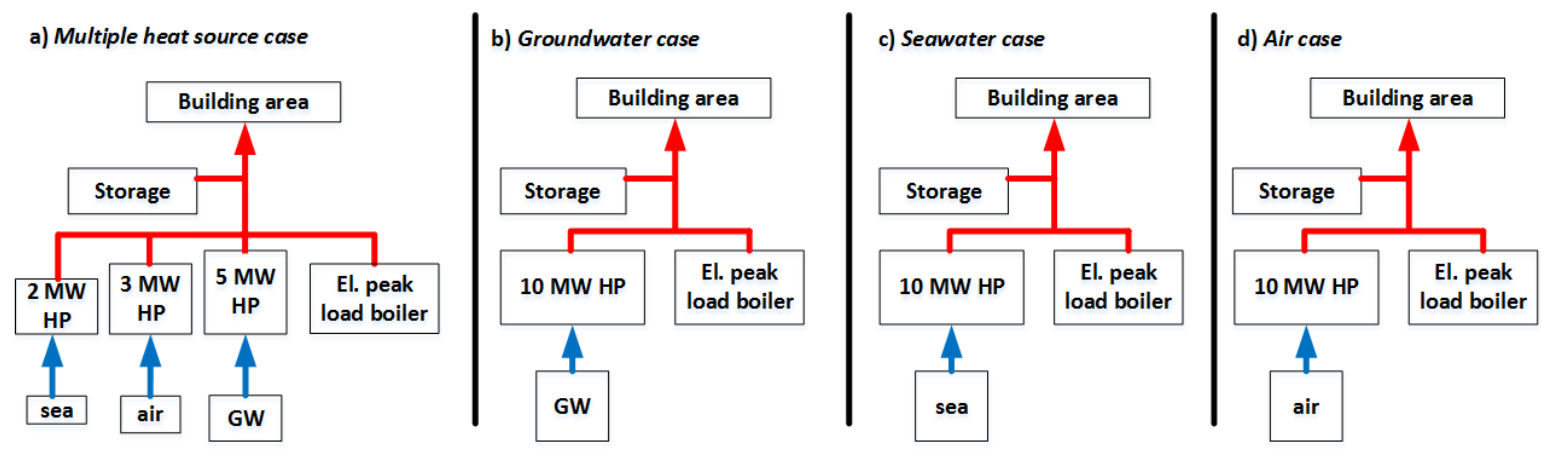

Fig. 1. System layout considering four different HP cases

The investigated system could be a relevant scenario for a new development area far from current DH networks, where expansion of existing DH networks may not be economically feasible, e.g. [35]. Purely electrified $\mathrm{DH}$ systems could become relevant for the integration of high shares of RES in the electricity sector, such as wind and solar energy. Input parameters used for the production units and storage are shown in Table 1. 
Table 1. Specifications of system parameters

\begin{tabular}{llr}
\hline Input parameter & Unit & Value \\
\hline Total HP capacity & \% of hourly maximum peak demand & 80 \\
Storage capacity & MWh & 15 \\
Storage heat loss factor & \% of stored heat & 0.1 \\
Electric peak load boiler capacity & \% of hourly maximum peak demand & 20 \\
COP peak, el. & - & 1 \\
Total pipe heat loss factor [3] & \% of total heat supply & 5 \\
\hline
\end{tabular}

\subsection{Numerical model}

The objective of the optimization process was to minimize the annual electricity consumption of all production units, $P_{\text {Sys, }}$ as shown in Eq. (1):

$$
\min P_{\text {sys }}=\sum_{n=1}^{N} \sum_{u=1}^{U} P_{u, n}=\sum_{n=1}^{N} P_{\text {sea }, n}+P_{\mathrm{GW}, n}+P_{\mathrm{air}, n}+P_{\text {peak }, n}
$$

Thereby, the optimization resulted in achieving highest seasonal system performance. The electricity consumption $P_{u, n}$ of each production unit $u$, including the three HPs and the electric peak load boiler, was calculated for each hour $n$ as:

$$
P_{u, n}=\frac{Q_{\operatorname{sink}, u, n}}{\operatorname{COP}_{u, n}}
$$

The sum of generated heat of each production unit $Q_{\text {sink, }, n}$ was for every hour $n$ in balance with the heat demand $Q_{\text {demand, } n}$, the pipe heat loss $Q_{\text {pipe,loss, } n}$ and the difference of stored and used heat from the storage $\left(Q_{\text {st,char }, n}-Q_{\text {st,dis, } n}\right)$, as stated in Eq. (3).

$$
\sum_{u=1}^{U} Q_{\text {sink }, u, \mathrm{n}}=Q_{\mathrm{demand}, n}+Q_{\mathrm{pipe,loss}, n}+Q_{\mathrm{st}, \mathrm{char}, n}-Q_{\mathrm{st}, \mathrm{dis}, n}
$$

The HPs generating the heat $Q_{\text {sink,j, } n}$ were limited by the hourly HP capacities $\dot{Q}_{\text {sink }, j, n}$, due to varying conditions of each heat source $j$.

The storage level of hour $n$ was determined by Eq. (4), which includes the storage level of the previous hour $Q_{\text {st,level,n-1}}$, the amount of heat the storage is charged and discharged with and the storage heat loss factor $f_{\text {loss }}$. The storage capacity was $15 \mathrm{MWh}$, as stated in Table 1.

$$
Q_{\text {st,level }, n}=Q_{\mathrm{st}, \text { level }, n-1}+Q_{\mathrm{st}, \mathrm{char}, n}-Q_{\mathrm{st}, \mathrm{dis}, n}-f_{\text {loss }} Q_{\mathrm{st}, \mathrm{level}, n}
$$

The COP of the electric peak load boiler is 1, as shown in Table 1. The COP of each HP, $\mathrm{COP}_{\mathrm{HP}, j, n}$, of a different heat source $j$ was calculated for every hour $n$ based on Eq. (5), Eq. (6) and Eq. (7) [36]: 


$$
\begin{gathered}
\operatorname{COP}_{\mathrm{HP}, j, n}=\eta_{L} \operatorname{COP}_{\mathrm{HP}, L, j, n}=\eta_{L} \frac{\bar{T}_{\mathrm{lm}, h, j, n}}{\bar{T}_{\mathrm{lm}, h, j, n}-\bar{T}_{\mathrm{lm}, c, j, n}} \\
\bar{T}_{\mathrm{lm}, c, j, n}=\frac{T_{c, i, j, n}-T_{c, o, j, n}}{\ln T_{c, i, j, n}-\ln T_{c, o, j, n}} \\
\bar{T}_{\mathrm{lm}, h, j, n}=\frac{T_{h, o, j, n}-T_{h, i, j, n}}{\ln T_{h, o, j, n}-\ln T_{h, i, j, n}}
\end{gathered}
$$

Equations (6) and (7) determine the logarithmic mean temperature of the cold side and the hot side of the HP, respectively, considering absolute temperatures in Kelvin and the natural logarithm. For this, the temperature glides, defined as the temperature difference between inlet and outlet flows from heat source and heat sink, were taken into account. $\mathrm{COP}_{\mathrm{HP}, L, j, n}$ represents the hourly $\mathrm{COP}$ of an associated Lorenz cycle, which was multiplied by the Lorenz efficiency, $\eta_{L}$, assumed to be $0.5[22,37,38]$.

The purpose of the developed model was to use it in the planning stage for a new-developed area. This makes it possible to account for varying COP and to assess the potential of multiple heat sources. A detailed HP model was not used, because it would limit its applicability to a specific HP design with a configuration that might be different from case to case.

\subsection{Heat sources}

Media properties of all heat sources were calculated for each hour using Engineering Equation Solver (EES) [39]. For all heat sources a temperature glide between inlet and outlet of $5 \mathrm{~K}$ was assumed [7]. However, a minimum allowable evaporator outlet temperature of seawater was set at $-1{ }^{\circ} \mathrm{C}$ to avoid freezing, which limits the glide in colder periods. The salinity of seawater is on average $35 \%$ with a freezing point at $-2{ }^{\circ} \mathrm{C}$ [40], whereas the salinity of the Baltic Sea depends on the location and depth, but is in general lower in concentration at around $15 \%$ o to $25 \%$ [ [41], resulting in freezing points of $-0.9{ }^{\circ} \mathrm{C}$ and $-1.4{ }^{\circ} \mathrm{C}$, respectively [40].

To avoid freezing during cooler periods, it was assumed that seawater was not pumped from the water surface, but instead from several meters depth, where the temperature in winter is higher. This is done for large-scale HPs in Oslo, Norway [42], and in Stockholm, Sweden, [43].

Seawater temperature measurements from 2015 and 2017 were provided from the National database (ODA) by the Danish Environmental Protection Agency, which is part of the Ministry of Environment and Food of Denmark [44]. Measurements at a depth of $10 \mathrm{~m}$ were used since the seawater depth near the investigated area is up to $11 \mathrm{~m}$ [41]. The measurements were taken near Copenhagen from the station $\mathrm{KBH} 431$ and further processed in MATLAB, version R2016a [45], to create an hourly temperature profile over the year. This was done by taking the mean values of the measurements of both years and performing a shape-preserving piecewise cubic interpolation. The resulting temperatures of this procedure and the measured temperatures at $10 \mathrm{~m}$ depth compared to the surface water temperature for the Danish Design Reference Year (DRY) [46] are presented in Fig. 2. In addition, the minimum seawater outlet temperature after the evaporator is indicated. As shown, the seawater temperature at $10 \mathrm{~m}$ is higher in winter and lower in summer compared to the temperature at the surface. From mid-January until mid-March, the temperature difference of $5 \mathrm{~K}$ cannot be obtained, which will have an effect on the extractable heat flow rate.

Groundwater was assumed to be accessed at around $100 \mathrm{~m}$ depth, where the temperature is fairly constant during the year: between $8{ }^{\circ} \mathrm{C}$ and $10{ }^{\circ} \mathrm{C}$ [38]. Its value was assumed to be $9{ }^{\circ} \mathrm{C}$. In addition, no influence of the groundwater temperature by return water was considered, since the return water was assumed to be released to the sea. The extraction of groundwater was close to the sea and thereby, seawater would naturally flow back 
to the groundwater reservoir over time. Reinjection of groundwater may be required at locations inland to avoid water level decrease or salinity incursions.

For air, hourly data for the DRY was used to represent typical conditions for the area of Copenhagen [46].

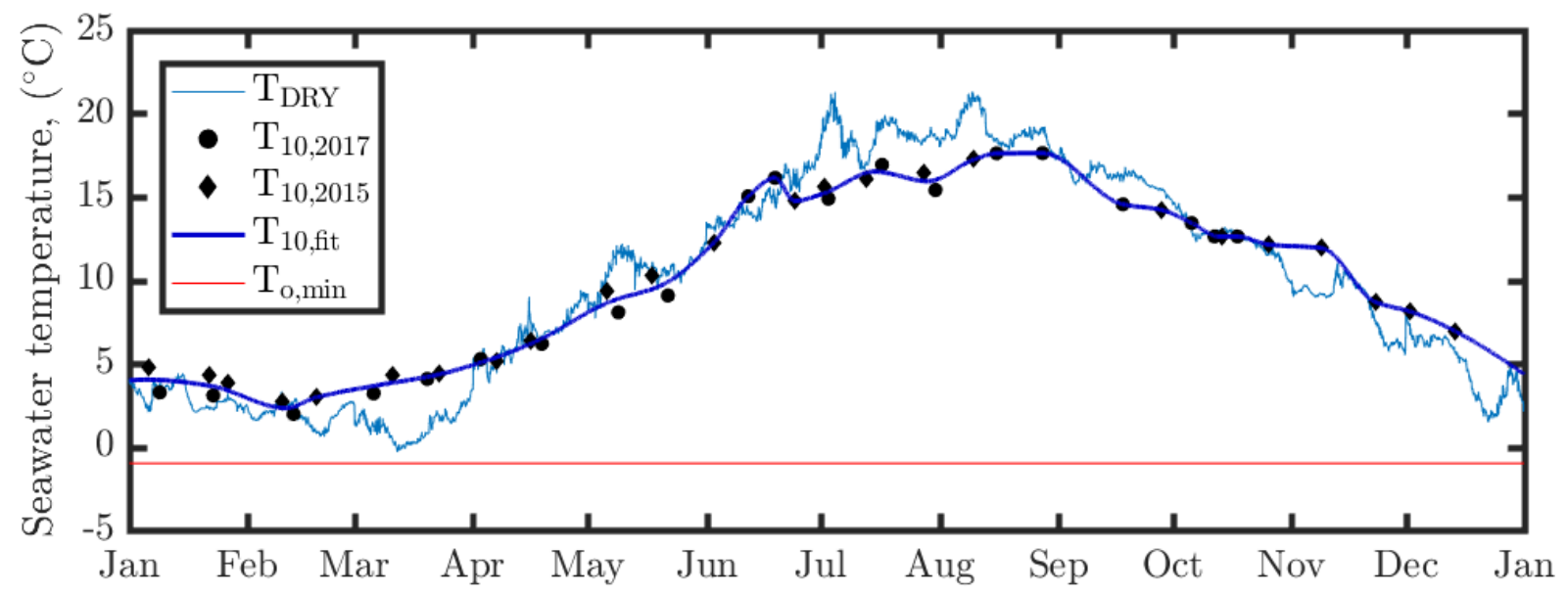

Fig. 2. Seawater temperature function, DRY and measurements near Copenhagen

\subsection{Calculation of extractable heat flow rates}

The HP capacity $\dot{Q}_{\text {sink, } d}$ was a given percentage of the maximum hourly heat demand of the system, as stated in Table 1. The HP should be able to supply this dimensioning capacity under design conditions. Design conditions were specified such that source inlet temperatures of $4{ }^{\circ} \mathrm{C}, 9{ }^{\circ} \mathrm{C}$ and $-12{ }^{\circ} \mathrm{C}$ were assumed for seawater, groundwater and air, respectively. A seawater inlet temperature of $4{ }^{\circ} \mathrm{C}$ was selected, because this temperature allows a $5 \mathrm{~K}$ temperature glide without the risk of freezing. An inlet temperature of $-12{ }^{\circ} \mathrm{C}$ was used for air, because this is the Danish design temperature for heating and cooling systems in buildings [47].

A DH network with design supply and return temperatures of $90^{\circ} \mathrm{C}$ and $35^{\circ} \mathrm{C}$ was assumed, as described later. Heat source and sink temperatures made it possible to calculate a design $\mathrm{COP}_{d, j}$ for a HP for each heat source $j$ using Eq. (5). The design heat flow rate of each heat source $\dot{Q}_{d \text {,source,j }}$ was then determined using Eq. (8), assuming no heat losses and a steady state energy balance across the HP [48]:

$$
\operatorname{COP}_{d, j}=\frac{\dot{Q}_{d, \text { sink }}}{\dot{W}_{\mathrm{HP}, j}}=\frac{\dot{Q}_{d, \text { sink }}}{\dot{Q}_{d, \text { sink }}-\dot{Q}_{d, \text { source }, j}} \Rightarrow \dot{Q}_{d, \text { source }, j}=\frac{\dot{Q}_{d, \text { sink }}}{\operatorname{COP}_{d, j}}\left(\operatorname{COP}_{d, j}-1\right)
$$

The design volume flow rate for each heat source was calculated as follows:

$$
\dot{V}_{d, \text { source }, j}=\frac{\dot{m}_{d, \text { source }, j}}{\rho_{d, \text { source }, j}}=\frac{\dot{Q}_{d, \text { source }, j}}{\rho_{d, \text { source }, j} c_{p, d, j}\left(T_{c, i, d, j}-T_{c, o, d, j}\right)}
$$

The design volume flow rate was then used to calculate the maximum extractable heat flow rate $\dot{Q}_{\text {source }, j, n}$ of each heat source $j$ at every hour $n$ for changes in temperatures, specific heat and density as:

$$
\dot{Q}_{\text {source }, j, n}=\dot{V}_{d, \text { source }, j} \rho_{\text {source }, j, n} c_{p, j, n}\left(T_{c, i, j, n}-T_{c, o, j, n}\right)
$$


These heat flow rates were not constrained due to scarcity of the individual heat sources. Instead, it was assumed that the HP cycle and ancillary equipment for the heat source were designed according to the design volume flow rate, which limited the extractable heat flow rate during the year.

The corresponding maximum HP capacities $\dot{Q}_{\text {sink }, j, n}$ for every hour were calculated based on Eq. (8) depending on changes in COP and extractable heat flow rates.

For the multiple heat source case, the assumed total HP capacity $\dot{Q}_{\text {sink,d }}$ was optimally distributed between the HPs using the three different heat sources as part of the optimization process according to Eq. (11) and Eq. (12). The extractable heat flow rates and corresponding HP capacities for every hour were then calculated as before.

$$
\begin{gathered}
\dot{Q}_{d, \text { sink }, \text { sea }}+\dot{Q}_{d, \text { sink }, \mathrm{GW}}+\dot{Q}_{d, \text { sink,air }}=\dot{Q}_{d, \text { sink }} \\
\dot{Q}_{d, \text { sink }, j} \leq \dot{Q}_{d, \text { sink }}
\end{gathered}
$$

\subsection{Performance indicators}

The four different cases were compared in terms of their performance, COPs, calculated for the HPs individually as well as for their implementation in the system. Additionally, the number of equivalent full load hours (FLH) during a year are shown.

An average $\mathrm{COP}_{\text {avg }}$ was calculated for the entire year taking the arithmetic mean of the $\mathrm{COP}_{\mathrm{HP}, j, n}$ for all hours, which was calculated by Eq. (5). The COPavg does neither take into account the duration when a HP was in operation, i.e. heat demand variations, nor the load.

A seasonal COP of HPs (SCOPHP) was therefore introduced, taking into account the operating hours of HPs:

$$
\operatorname{SCOP}_{\mathrm{HP}}=\frac{Q_{\text {sink }, \mathrm{HP}, \mathrm{tot}}}{P_{\mathrm{HP}, \mathrm{tot}}}=\frac{\sum_{n=1}^{N} Q_{\text {sink,sea }, n}+Q_{\text {sink }, \mathrm{GW}, n}+Q_{\text {sink }, \mathrm{air}, n}}{\sum_{n=1}^{N} P_{\mathrm{sea}, n}+P_{\mathrm{GW}, n}+P_{\mathrm{air}, n}}
$$

The $\mathrm{SCOP}_{\mathrm{HP}}$ was calculated as the ratio of total generated heat $Q_{\text {sink,HP,tot }}$ and total consumed electrical energy $P_{\mathrm{HP}, \text { tot }}$ of all HPs for the entire year.

Similarly to Eq. (13), a SCOP of the system ( $\left.\mathrm{SCOP}_{\text {Sys }}\right)$ was calculated by considering the total generated heat and consumed electrical energy of all production units $u$ of the system, including HPs and peak load unit:

$$
\operatorname{SCOP}_{\text {Sys }}=\frac{Q_{\text {sink }, \text { sys }, \text { tot }}}{P_{\text {sys,tot }}}=\frac{\sum_{n=1}^{N} Q_{\text {sink }, \text { sea }, n}+Q_{\text {sink }, \mathrm{GW}, n}+Q_{\text {sink }, \text { air }, n}+Q_{\text {peak }, n}}{\sum_{n=1}^{N} P_{\text {sea }, n}+P_{\mathrm{GW}, n}+P_{\text {air }, n}+P_{\text {peak }, n}}
$$

FLH represent the number of hours a production unit would operate at its full design capacity during the year. $\mathrm{FLH}_{u}$ were defined as the ratio of generated heat $Q_{\operatorname{sink}, u, n}$ for a production unit $u$ and hour $n$ and the design capacity $\dot{Q}_{\operatorname{sink}, u, d}$, accumulated over the year:

$$
\mathrm{FLH}_{u}=\sum_{n=1}^{N} \frac{Q_{\operatorname{sink}, u, n}}{\dot{Q}_{d, \operatorname{sink}, u}}
$$

\subsection{Case description}

The investigated case area was the Nordhavn area, which is a new residential and commercial development region in Copenhagen. It is one of the largest development districts in Europe and is intended to demonstrate 
how sustainable living can be achieved [49]. Nordhavn will be gradually expanded until 2060 to accommodate 40,000 inhabitants and 40,000 jobs in a floor area of 3.5 million $\mathrm{m}^{2}$ [49]. The heat demand considered for this study was for the already developed part of Nordhavn by 2017 and the construction phase stage II starting in 2018 with $669,600 \mathrm{~m}^{2}$ total floor area [50,51].

The buildings in the area were designed for supply temperatures of $70^{\circ} \mathrm{C}$ and return temperatures of $40^{\circ} \mathrm{C}[50]$. During the current construction phase, $\mathrm{DH}$ in the existing part of Nordhavn is still supplied by the existing $\mathrm{DH}$ network of Greater Copenhagen and its production units, mainly CHP plants. Measured supply and return temperatures of a building in Nordhavn depending on the ambient temperature for 2017 are shown in Fig. 3 [52]. The supply temperatures reached as low temperatures as $65^{\circ} \mathrm{C}$ in summer, but also temperatures up to $95{ }^{\circ} \mathrm{C}$ for very cold ambient temperatures. Supply temperatures below $70{ }^{\circ} \mathrm{C}$ and $80{ }^{\circ} \mathrm{C}$ occurred in $26 \%$ and $79 \%$ of the time during the year, respectively. Only during short periods the supply temperature was higher.

A weather compensation curve was created based on the temperature measurements, as indicated in Fig. 3 . The supply temperature $\left[{ }^{\circ} \mathrm{C}\right]$ as a function of ambient temperature is shown in Eq. 16 :

$$
T_{\text {supply }, n}=\max \left\{\begin{array}{l}
70 \\
\min \left\{\begin{array}{l}
-2 * T_{\text {air }, n}+90 \\
90
\end{array}\right.
\end{array}\right.
$$

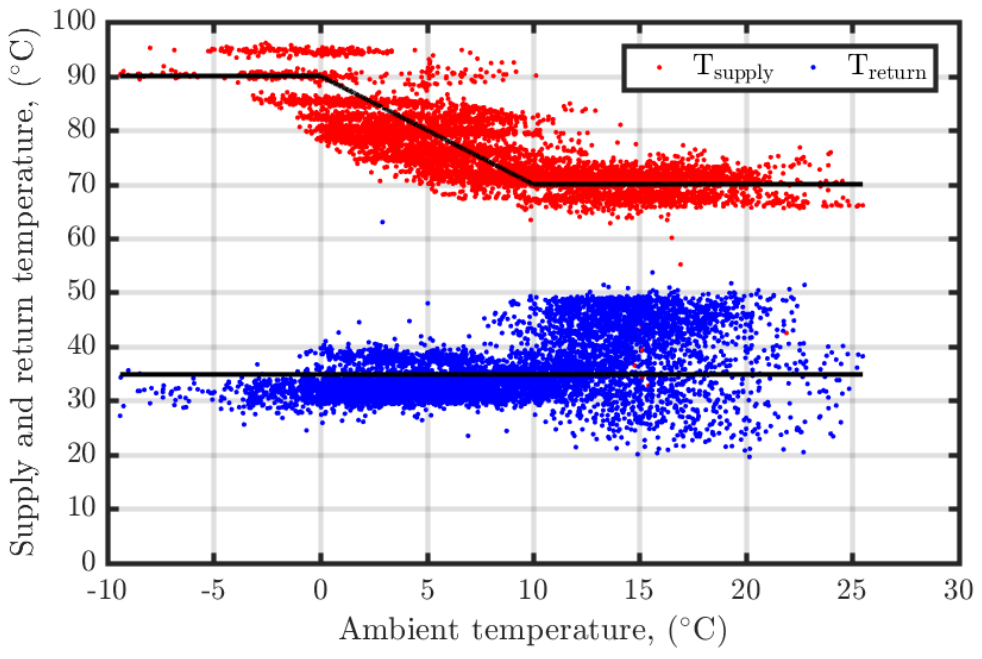

Fig. 3. DH supply and return temperatures based on measurements in 2017 [52]

For cold ambient temperatures, the supply temperature was kept high and the return temperature low to supply a high heat demand. For ambient temperatures between $0{ }^{\circ} \mathrm{C}$ and $10{ }^{\circ} \mathrm{C}$, the heat demand became lower. Therefore, the supply temperature was decreased to reduce heat losses until the minimum temperature was reached while still ensuring no risk of legionella bacteria. The return temperature was kept constant at the mean value of the measurements of $35^{\circ} \mathrm{C}$.

It was assumed that the investigated area consisted only of residential buildings complying with the Danish Building Regulation 2015 [53]. The space heating (SH) demand was calculated, as in Foteinaki et al. [54], for a specific apartment located in Nordhavn with $130 \mathrm{~m}^{2}$ floor area using the software IDA Indoor Climate and Energy, version 4.7 [55]. The DRY for the region of Copenhagen was used as input to represent typical weather conditions [46]. The simulation was performed on an hourly basis for an entire year and resulted in a SH demand of $22.0 \mathrm{kWh} / \mathrm{m}^{2} / \mathrm{a}$.

DHW consumption was based on a daily tapping profile for an European family with shower use consuming 100 I at $60{ }^{\circ} \mathrm{C}$ [56]. The coincidence of hot water use was based on a normal distribution with a standard deviation of 
60 min for the given profile for the total number of 5151 apartments. By doing so, the DHW consumption accounts for differing inhabitant behaviour. An overview of the differences in DHW consumption for the entire area is shown in Fig. 4. Hourly consumption was preferred to use instead of a constant one, since this will identify the actual hours of peak demand. The dark columns in Fig. 4 indicate DHW consumption for full coincidence of hot water tapping. The light columns consider a tapping profile with basic assumptions for the standard deviation of tapping. In addition, seasonal variations of DHW consumption were taken into account, based on Frederiksen and Werner [57]. Their findings were based on measurements in Swedish residential multi-dwelling buildings. The relative hot water flow demand for every month considered for the calculations in this study may be seen from Table 2. The DHW demand profile was used to represent the entire area, which resulted in a DHW demand of $16.1 \mathrm{kWh} / \mathrm{m}^{2} / \mathrm{a}$.

The maximum peak demand was $12.4 \mathrm{MWh} / \mathrm{h}$. Pressure losses and the electricity consumption of auxiliary equipment such as pumps were neglected.

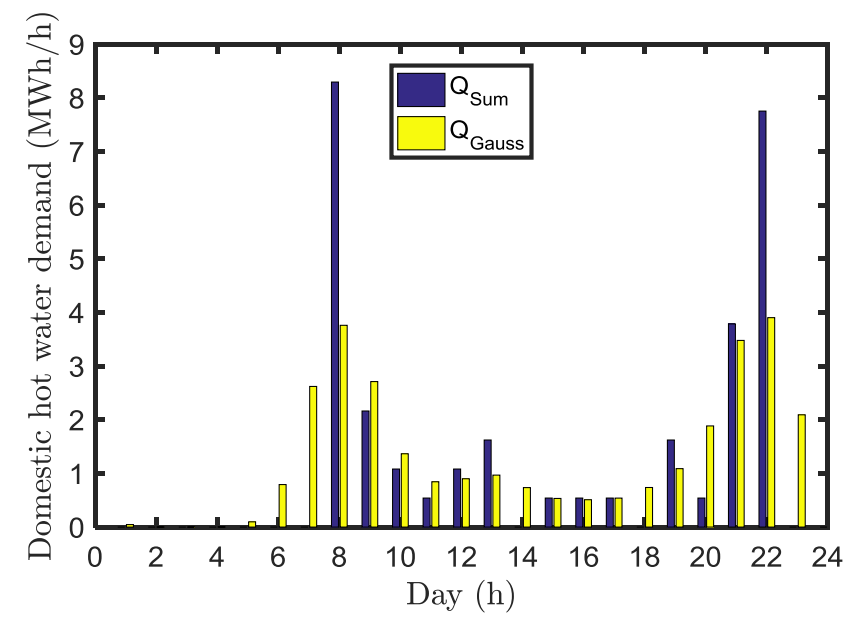

Fig. 4. Daily distribution of DHW demand for entire area based on normal distribution (Gauss) and tapping at the same time (Sum)

Table 2. Monthly relative hot water flow demand [57]

\begin{tabular}{ccccccccccccc}
\hline Month & Jan & Feb & Mar & Apr & May & Jun & Jul & Aug & Sep & Oct & Nov & Dec \\
\hline Factor & 1.1 & 1.1 & 1.1 & 1.1 & 0.9 & 0.85 & 0.7 & 0.75 & 1.0 & 1.0 & 1.1 & 1.1 \\
\hline
\end{tabular}

\subsection{Sensitivity analysis}

A sensitivity analysis was performed to investigate how the model results change under different conditions.

\subsection{1. $\quad$ Change of heat source proportion}

The optimal proportion of seawater, groundwater and air for the multiple heat source case was found using linear programming. The proportion of each heat source was varied in order to identify an acceptable combination that would still result in a high system performance.

\subsubsection{Low-energy building requirements}

The total energy consumption of the supplied area was $38.1 \mathrm{kWh} / \mathrm{m}^{2} / \mathrm{a}$ as described earlier, which is slightly above the limit of $30 \mathrm{kWh} / \mathrm{m}^{2} /$ a required by the Danish Building Regulation 2015 [53]. The Danish Building Regulation 2020 requires an even lower annual energy demand for residential buildings of $20 \mathrm{kWh} / \mathrm{m}^{2} / \mathrm{a}$ [58]. 
The DHW demand is unlikely to decrease. Therefore, the SH demand was varied. The developed model was applied for near-future low-energy buildings by reducing the hourly SH demand by $50 \%$ to investigate how this would affect the performance and FLH of HPs for the different cases. The total annual energy consumption turned out to be $27.1 \mathrm{kWh} / \mathrm{m}^{2} / \mathrm{a}$.

\subsubsection{Warm and cold climates}

The model was applied to typical climate conditions near Copenhagen, Denmark. The temperatures of heat sources might change for different climate zones. Therefore, the model was applied to a warm and a cold region by varying the heat source temperatures and the SH demand as shown in Table 3. The DH supply temperatures were adjusted according to the ambient air temperatures using the same weather compensation curve as in Fig. 3. The maximum hourly peak demand varied, according to the changes in $\mathrm{SH}$ demand, to $8.1 \mathrm{MWh} / \mathrm{h}$ and 17.2 $\mathrm{MWh} / \mathrm{h}$ for the warm and cold region, respectively.

Table 3. Variation of heat source temperatures and SH demand for warm and cold climates

\begin{tabular}{ccccc}
\hline Climate region & Groundwater & Seawater & Air & SH demand \\
\hline Cold & $\mathrm{T}_{\mathrm{GW}}-2{ }^{\circ} \mathrm{C}$ & $\mathrm{T}_{\text {sea }, h}-3{ }^{\circ} \mathrm{C}$ & $\mathrm{T}_{\text {air }, h}-5{ }^{\circ} \mathrm{C}$ & $\dot{Q}_{\text {demand,SH}} \cdot 1.5$ \\
Warm & $\mathrm{T}_{\mathrm{GW}}+2{ }^{\circ} \mathrm{C}$ & $\mathrm{T}_{\mathrm{sea}, h}+3{ }^{\circ} \mathrm{C}$ & $\mathrm{T}_{\mathrm{air}, h}+5{ }^{\circ} \mathrm{C}$ & $\dot{Q}_{\mathrm{demand}, \mathrm{SH}} \cdot 0.5$ \\
\hline
\end{tabular}

\subsubsection{Change of temperature glide of heat source and total HP capacity}

The temperature glide of the heat sources between evaporator inlet and outlet was reduced from $5 \mathrm{~K}$ to $3 \mathrm{~K}$. This would result in no limitation in extractable heat flow rate of seawater in winter, because the minimum seawater temperature was above $2{ }^{\circ} \mathrm{C}$ and the acceptable temperature at the evaporator outlet was $-1{ }^{\circ} \mathrm{C}$. The total HP capacity was fixed at $80 \%$ of the hourly peak demand. This value was varied, in addition, between $0 \%$ and $100 \%$ to determine which effect it might have on the different heat source cases investigated. The capacity of the electric peak load boiler was changed accordingly.

\subsubsection{Change of storage capacity and Lorenz efficiency}

The storage capacity was varied between $0 \mathrm{MWh}$ and $15 \mathrm{MWh}$ and the Lorenz efficiency was changed by $\pm 20 \%$ to $40 \%$ and $60 \%$ to investigate how these variations would change the seasonal performance of the system for the four different cases.

\section{Results}

First, the characteristics of the three heat sources are presented by comparing the extractable heat flow rates during the year according to design specifications and by an analysis of hourly changes in COP for each HP using a different heat source. Afterwards, the operation of the multiple heat source case is shown for different times of the year, which indicates the changing prioritization of heat sources depending on the outside conditions. Performance indicators of the multiple heat source case are then presented and compared with the ones of the three reference cases based on single heat sources. Finally, the results of the sensitivity analysis are shown.

\subsection{Extractable heat flow rates}

The total HP capacity was $9.9 \mathrm{MW}$ representing $80 \%$ of the peak demand, as stated in Table 1 . According to Eq. (9), the design volume flow rates for the three reference cases using groundwater, seawater and air were: $1156 \mathrm{~m}^{3} / \mathrm{h}, 1103 \mathrm{~m}^{3} / \mathrm{h}$ and $795 \mathrm{~m}^{3} / \mathrm{s}$. 
Based on the design volume flow rates it was possible to determine the maximum extractable heat flow rate of each heat source in every hour using Eq. (10). The differences in heat flow rates during the year and the daily average heat demand are shown in Fig. 5.

The maximum extractable heat flow rate of the groundwater (green) is constant during the entire year, since the temperature, specific heat and density do not vary. The heat flow rate of the air (orange) varies slightly during the year depending on temperature-dependant changes in specific heat and density. The extractable heat flow rate is lower than for the groundwater due to the lower design $\mathrm{COP}_{d}$ for air, i.e. more of the heat demand is covered by the power consumption of the HP. The heat flow rate of the seawater (blue) is constant from mid-March until mid-January. During parts of the cold heating season, however, the seawater heat flow rate drops from 6.4 MW down to 4.2 MW in the middle of February. Because the lowest values of seawater heat flow rate occur in periods of high heat demand, the seawater HP cannot supply what it was designed for during periods when it is needed the most. The reason for the decrease in extractable heat flow rate is the lower limit of seawater temperature at the evaporator outlet, which was set at $-1{ }^{\circ} \mathrm{C}$. Accordingly, the temperature glide becomes very small for seawater temperatures below $4{ }^{\circ} \mathrm{C}$.

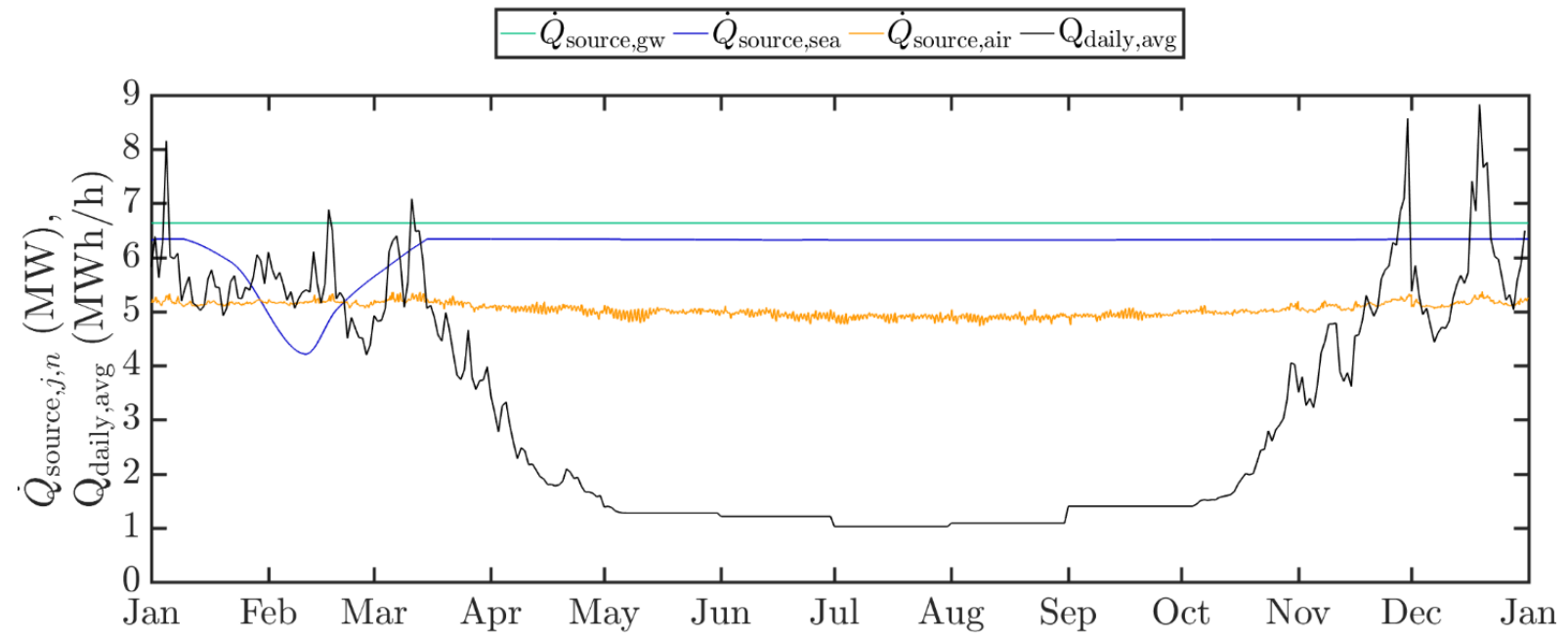

Fig. 5. Average daily heat demand and extractable heat flow rates for each heat source for every hour

\subsection{COP of HPs for different heat sources}

The hourly values for the $\mathrm{COP}_{\mathrm{HP}, \mathrm{j}, \mathrm{n}}$ determined by Eq. (5) for a HP based on seawater, groundwater or air, and the daily average heat demand are shown in Fig. 6. As shown, the hourly COPs for the HPs using different heat sources were low in winter and higher in summer. The COPs however differed for different heat sources used.

The groundwater HP showed the highest COP from mid-December until April. The COP fluctuated only slightly depending on the changes in $\mathrm{DH}$ supply temperature, since the groundwater temperature was constant. The COP was therefore constant during summer for minimum DH supply temperatures. The arithmetic mean $\mathrm{COP}_{\text {avg,gw }}$ was 3.36 and was the lowest compared to the $\mathrm{COP}_{\text {avg }}$ based on the other two heat sources.

The hourly COP of the air HP fluctuated the most during the year. The highest values occurred during summer with a few considerable peaks above 5 due to high ambient temperatures. During winter the COP of the air HP was low when the ambient air was cold and decreased below 2.5 during some hours. Fluctuations of the COP were observed not only during the year, but also on a daily basis. Its minimum was $36 \%$ lower and its maximum $75 \%$ higher than the arithmetic mean $\mathrm{COP}_{\text {avg,air }}$ at 3.49 . 
The COP of the seawater HP followed a similar trend during the year than the one of the air HP, but with smaller amplitude and without daily variations. The reason was that changes in seawater temperature were much smaller than those of ambient air [46]. It was further noted that the COP of the seawater HP was the largest during the autumn months until mid-November, because the seawater temperature at $10 \mathrm{~m}$ depth was affected at a later point in time by colder ambient temperatures. The minimum COP of the seawater HP was $22 \%$ lower and the maximum COP was $25 \%$ higher than the arithmetic mean $\mathrm{COP}_{\text {avg,sea }}$ at 3.52 .

By comparing the arithmetic mean COP values, it may be noted that the COPs of the air and seawater HP are higher than the one from the groundwater HP. However, the seasonal performance of the HPs may still differ, since the operating hours of HPs were not taken into account. The next step was to evaluate HP performance in terms of how well it was able to fulfil heat requirements.

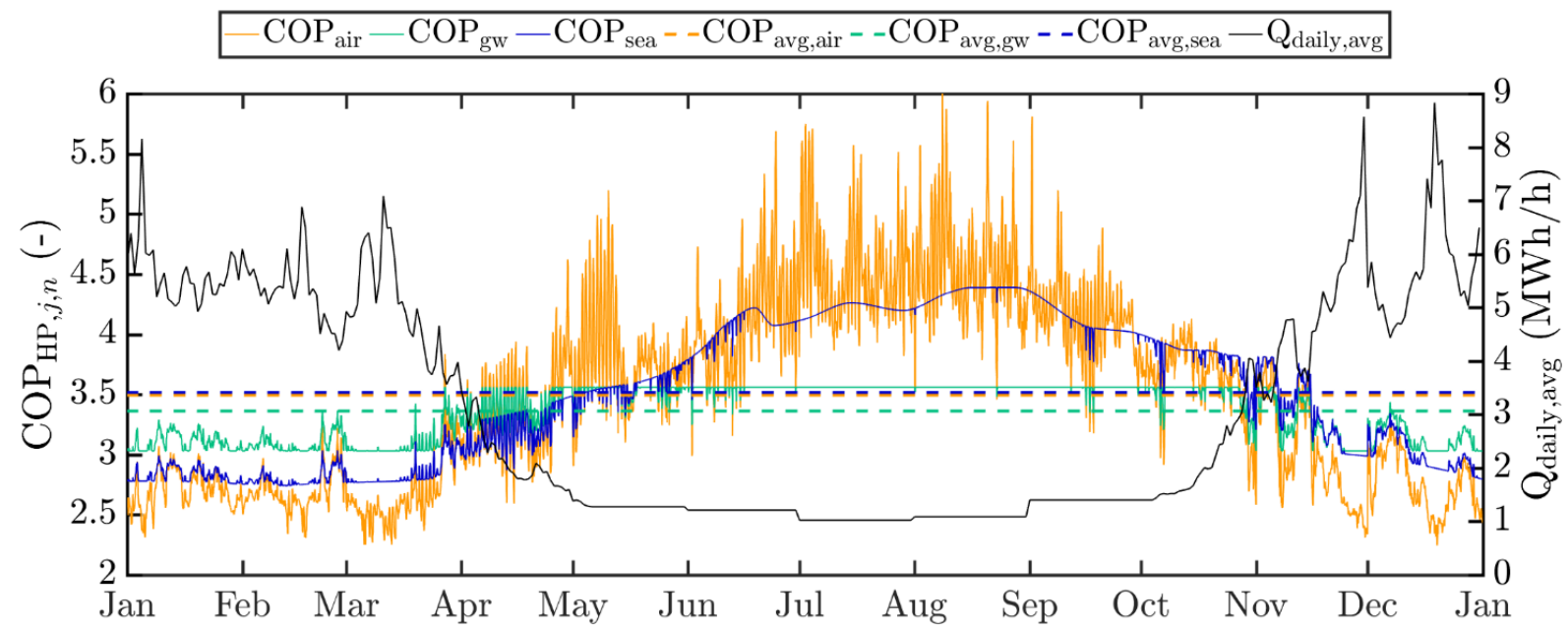

Fig. 6. $\mathrm{COP}_{\mathrm{HP}, j, n}$ of HPs based on individual heat sources and daily average heat demand

As shown in Fig. 6, the daily average heat demand was high from November until April with a few significant peaks. On the other hand, the heat demand was very low from May to October, when only heat for DHW had to be supplied. Thus, seawater and air could only be used to a limited extent in summer, which was when they had a high COP. During winter, groundwater would be the best heat source to use, because of its high COP. This result indicates an optimum for using several heat sources.

\subsection{The multiple heat source case}

The optimum combination of heat source proportions and resulting HP capacities for the multiple heat source case are shown in Table 4.

Table 4. Optimal heat source proportions and HP capacities for the multiple heat source case

\begin{tabular}{lcccc}
\hline Parameter & Groundwater & Seawater & Air & Total \\
\hline Heat source proportion, \% & 63 & 14 & 23 & 100 \\
HP capacity, MW & 6.2 & 1.4 & 2.3 & 9.9 \\
\hline
\end{tabular}

The HP capacities were found using linear programming to minimize total electricity consumption over the entire year. Accordingly, the highest COP of the individual HPs for every hour was chosen to meet the characteristic heat demand over the year. The capacity of the groundwater HP was considerably higher than those of seawater 
and air HPs, so that it could supply most of the heat demand very efficiently in winter. On the other hand, the capacities of the seawater and air HPs were smaller but still sufficient to cover the DHW demand during summer and partly during spring and autumn.

The operation of the HPs for the multiple heat source case is shown in Fig. 7 for four characteristic weeks during the year. The generation of heat based on the different HPs and the discharging of the storage is indicated by colours. In addition, the hourly COPs and heat demand are shown. The scale of the ordinate of the subplots differs to visualize the operation better during periods of low heat demand. The operation for the entire year can be found in Appendix A.

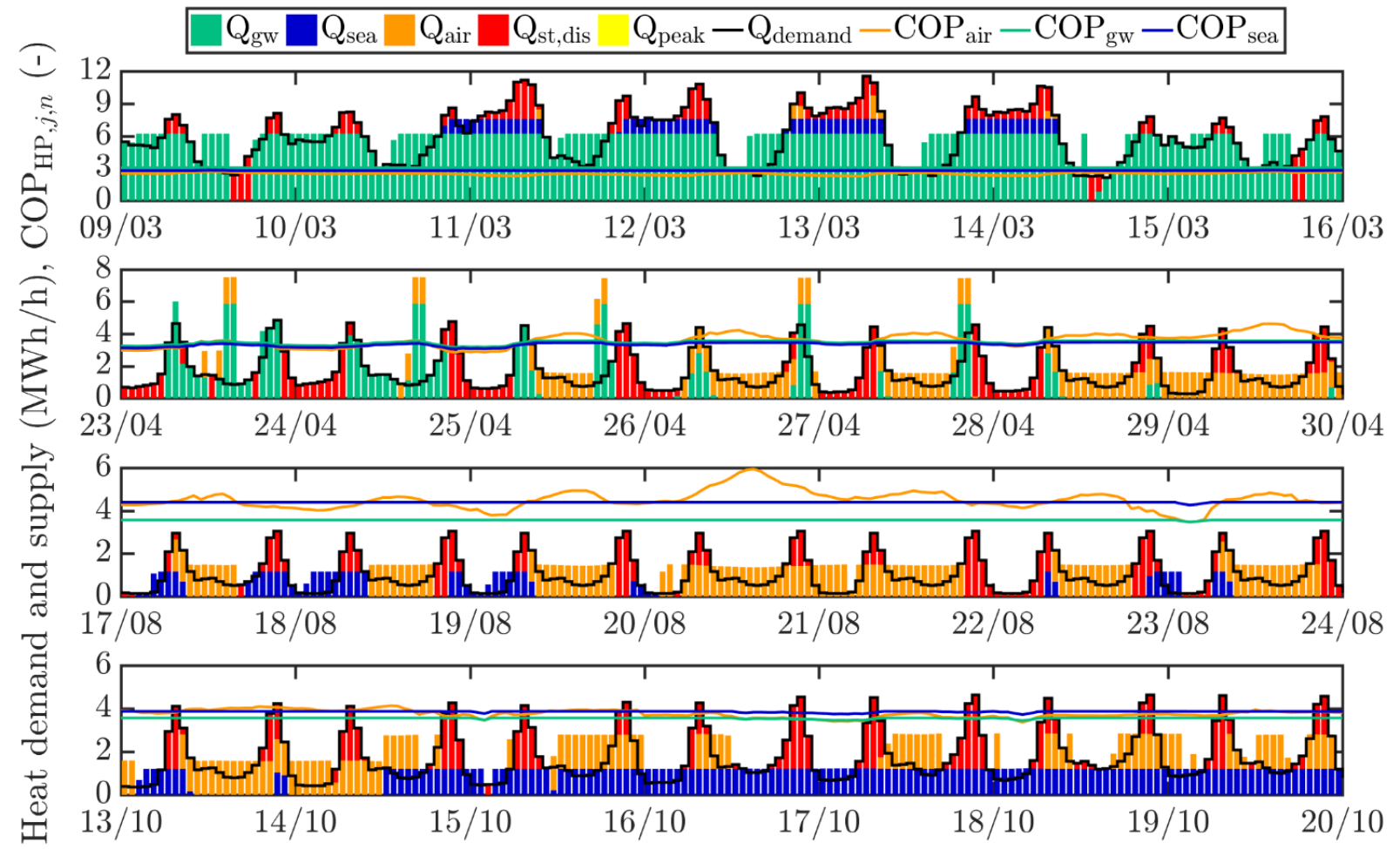

Fig. 7. Operation of HPs for the multiple heat source case during four weeks

The week in March represents the typical operation of the HPs during winter conditions. The groundwater HP was preferred because of its high COP. Its capacity was appropriate, because the HP was operated at full capacity at many hours for this period. The groundwater HP was also used to charge the storage, which is indicated by the green bars overshooting the heat demand in certain hours. Peak demands could then be fulfilled by discharging the storage. The seawater and/or air HPs were used in addition during very high peak demands from $11^{\text {th }}$ until $15^{\text {th }}$ of March, because the storage capacity limit was reached before.

The week in April represents the typical operation of the HPs during spring. The days between the $25^{\text {th }}$ and $30^{\text {th }}$ of April were warmer than the ones before, so that the COP of the air HP exceeded the one of the groundwater and seawater HPs during daytime. During night-time, however, the COP of the groundwater HP was sometimes still higher. In addition, the groundwater HP was also required, because the SH demand during spring resulted in higher peak demands than in summer when only DHW was needed. The capacity of the air HP was not large enough to cover these peak demands entirely. Consequently, both HPs were in operation depending on the ambient conditions and required heat supply. The groundwater HP was either used directly during peak hours or by the means of storage. The seawater HP was not in operation. 
The week in August shows the characteristic operation of the HPs in summer. The COP of the air HP was much higher than for the other HPs on sunny days like the $20^{\text {th }}$ of August. The air HP was in operation at almost all times at full load to cover the DHW demand. The capacity of this HP was appropriate, because no additional HP with lower COP had to be used. The peak demands were covered by storage that was charged using the air HP as well. The maximum capacity of the air HP during summer was lower than the design capacity, because the COP in summer was higher than for design conditions. This resulted in less electricity consumption, but more heat source usage, which was limited by its design volume flow rate. When the temperature in the night dropped for colder days in summer, the COP of the air HP decreased below the one of the seawater HP. Consequently, the latter one was in operation during these periods to cover peak heat demands. The groundwater HP was not used at all due to its lower COP.

The week in October shows how usual operation of the different HPs was during autumn. The outdoor temperatures were already so low so that the COP of the air HP dropped below the one of the seawater HP, since it takes longer until the cold temperatures affect the seawater at $10 \mathrm{~m}$ depth. The seawater temperatures were still above the one of groundwater for this period, as shown in Fig. 2. Consequently, the seawater HP was operated mostly at full load. The air HP was used to cover the peak demands directly or to charge the storage during daytime. The groundwater HP was still not in use.

Deciding which of the different HPs should be in operation could be based on temperature sensors for the different heat sources. The groundwater and the seawater temperature are fairly constant on daily basis and the air temperature could be measured and also be forecasted for the next day or hours. This would make it possible to decide on an operation schedule well in advance.

\subsection{Performance indicators of all four HP cases}

The multiple heat source case is compared to the three single heat source cases, based on the performance indicators, as shown in Table 5. The parameters shown are: the arithmetic mean $\mathrm{COP}_{\text {avg, }} \mathrm{SCOP}_{\mathrm{HP}}$ of the HPs based on the hours of operation, $\mathrm{SCOP}_{\text {Sys }}$ of the entire system including peak load unit where applicable, and the FLH of each HP and electric peak load unit.

Table 5. Comparison of performance indicators for different heat source cases

\begin{tabular}{lcccc}
\hline Parameter & $\begin{array}{c}\text { Multiple heat source } \\
\text { case (GW/sea/air) }\end{array}$ & $\begin{array}{c}\text { Groundwater } \\
\text { case }\end{array}$ & $\begin{array}{c}\text { Seawater } \\
\text { case }\end{array}$ & $\begin{array}{c}\text { Air } \\
\text { case }\end{array}$ \\
\hline Average COPavg, - & 3.41 & 3.36 & 3.52 & 3.49 \\
SCOP $_{\text {HP, }}-$ & 3.32 & 3.22 & 3.13 & 2.97 \\
FLH HP, h & $3139 / 2226 / 1846$ & 2707 & 2707 & 2711 \\
FLH peak boiler, h & 0 & 0 & 1 & 0 \\
SCOP $_{\text {sys, }}$ & 3.32 & 3.22 & 3.13 & 2.97 \\
\hline
\end{tabular}

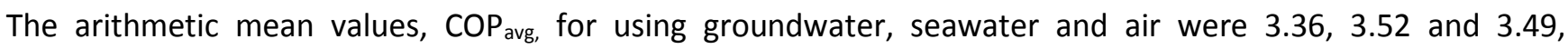
respectively. The resulting average COP for the multiple heat source case based on the capacities of the individual HPs was 3.41.

The SCOPHP decreased significantly by $11 \%$ and $15 \%$ when only seawater and air were used as heat sources compared to the arithmetic mean $\mathrm{COP}_{\text {avg, }}$ which does not consider a varying heat demand. Such a large decrease was not observed for the groundwater case (4\%) or the multiple heat source case (3\%).

The SCOPHP and the $\mathrm{SCOP}_{\text {Sys }}$ were similar, because the peak load boiler was not in operation apart from a very short time in the seawater case to compensate the reduction in extractable heat flow rate during some cold periods. 
The number of FLH was fairly constant for the reference cases. For the multiple heat source case, the FLH varied for the different HPs, because the HP with highest COP was always preferred over the other two, which changed for the heat sources during the year. Even though, the groundwater HP was not in operation during five months, the FLH were still higher than for the groundwater case, because the capacity was well chosen. Peak demands could be supplied by the additional use of the seawater HP.

Overall, it can be seen that the multiple heat source case had the highest SCOPSys of 3.32. The performance of the groundwater case was not far from this optimum, but still $3 \%$ lower. The seawater case had a reduction in system performance by $6 \%$ while the difference for the air case was even larger (11\%). This indicates that a combination of heat sources can yield in better system performance. Thereby, locally constrained heat sources may not be seen as obstacles, since they can be complemented by other heat sources and even keep the performance high. The results also show that groundwater was the preferred single heat source to use if no constraints exist in extracting it.

\subsection{Sensitivity analysis}

\subsubsection{The proportion of each heat source}

The effect on $\mathrm{SCOP}_{\text {sys }}$ of varying the proportion of each heat source for the multiple heat source case is shown in Fig. 8. Each point at the ternary diagram represents one combination of HP capacities for the three heat sources. The colours indicate the $\mathrm{SCOP}_{\text {sys }}$ of the system. The three reference cases based on a single heat source are shown in the corners.

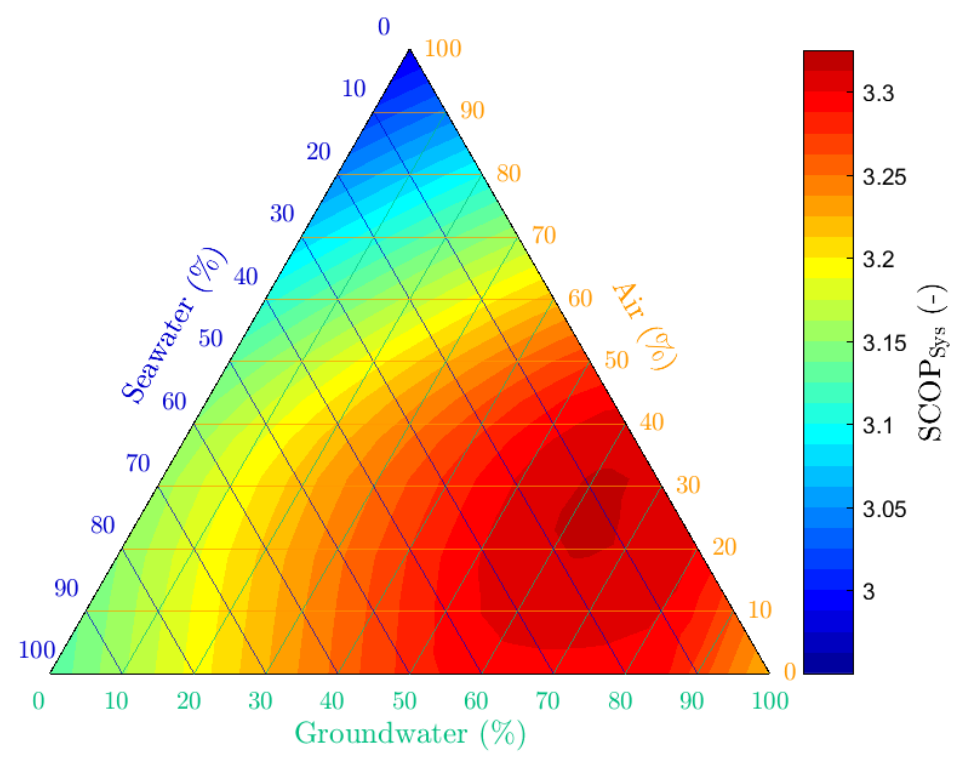

Fig. 8. Variation of heat source proportions

It may be seen from Fig. 8 that an optimum region exists that improves the system performance compared to the reference cases. For achieving high system performance, the groundwater HP capacity should be between $50 \%$ and $80 \%$, while the seawater HP capacity may be between $0 \%$ and $35 \%$ and the air HP capacity between $5 \%$ and $40 \%$. It may be seen that it is advantageous to include an air HP in a system with a capacity large enough to cover the DHW demand, in this case around $20 \%$ of the total HP capacity resulting in $2 \mathrm{MW}$. 


\subsubsection{Low-energy building requirements}

The results of supplying heat to near-future low-energy buildings with reduced $\mathrm{SH}$ demand by $50 \%$ can be seen in Table 6.

Table 6. Change of FLH and SCOPsys for supplying heat to low-energy buildings

\begin{tabular}{lcccc}
\hline Parameter & $\begin{array}{c}\text { Multiple heat source } \\
\text { case (GW/sea/air) }\end{array}$ & $\begin{array}{c}\text { Groundwater } \\
\text { case }\end{array}$ & $\begin{array}{c}\text { Seawater } \\
\text { case }\end{array}$ & $\begin{array}{c}\text { Air } \\
\text { case }\end{array}$ \\
\hline FLH HP, h & $3442 / 2858 / 2060$ & 2933 & 2933 & 2938 \\
Change in FLH HP, h & $303 / 632 / 214$ & 226 & 226 & 227 \\
SCOPSys, - & 3.38 & 3.26 & 3.20 & 3.08 \\
\hline
\end{tabular}

The optimum proportion of heat sources for the multiple heat source case changed to $56 \%, 11 \%$ and $31 \%$ for groundwater, seawater and air, respectively. This resulted in an improvement of $2 \%$ in SCOP sys $_{\text {compared to the }}$ case with $100 \%$ SH demand. This improvement was higher than for the groundwater case, so that the difference in system performance between these two cases increased from $3.0 \%$ to $3.6 \%$. The SCOP Sys $_{\text {of }}$ the air case improved with $4 \%$ more than for the other cases, because the COP of the HPs using air were lower in winter when the SH demand was reduced. In addition, the increase in FLH was also higher for the multiple heat source case than for any of the reference cases, which indicates that the heat sources were used in a better way.

The DHW demand contribution to the total annual energy consumption changed from $42 \%$, for the existing but new buildings, to $59 \%$ for near-future low-energy buildings. The results of the changes in SCOPsys indicate that HPs based on heat sources with a better COP in summer than in winter increase in performance when the proportion of DHW of the total energy consumption increases.

Overall, it can be said that a combination of heat sources used by HPs to supply heat might be more beneficial for future-low energy buildings with a flatter heat demand profile over the year so that the advantages of different heat source characteristics can be exploited more.

\subsubsection{Warm and cold climate conditions}

The changes in SCOP sys for the warm and cold climates are shown in Table 7.

Table 7. SCOP Sys $_{\text {for }}$ warm climate

\begin{tabular}{cccccc}
\hline Climate & Parameter & $\begin{array}{c}\text { Multiple heat } \\
\text { source case }\end{array}$ & $\begin{array}{c}\text { Groundwater } \\
\text { case }\end{array}$ & $\begin{array}{c}\text { Seawater } \\
\text { case }\end{array}$ & $\begin{array}{c}\text { Air } \\
\text { case }\end{array}$ \\
\hline Warm & SCOPSys, $_{\text {C }}$ & 3.78 & 3.55 & 3.55 & 3.56 \\
Cold & SCOP $_{\text {Sys },-}$ & 3.05 & 3.00 & 2.11 & 2.62 \\
\hline
\end{tabular}

For the warm climate, the optimum proportion of heat sources for the multiple heat source case changed to $58 \%, 2 \%$ and $40 \%$ for groundwater, seawater and air, respectively. This indicates that seawater played a minor role, because of the high air temperatures, and would probably be completely avoided in reality. This may be seen by the high proportion of air. The $\mathrm{SCOP}_{\text {sys }}$ of the multiple heat source case increased significantly by $14 \%$ and became by far the best performing case. The reference cases also improved in performance, but they all reached a maximum $\mathrm{SCOP}_{\text {sys }}$ of 3.55 to 3.56, which was $6 \%$ less than for the multiple heat source case. Seawater and air became competitive heat sources compared to groundwater.

For the cold climate, the optimum proportion of heat sources for the multiple heat source case changed to $74 \%$, $18 \%$ and $8 \%$ for groundwater, seawater and air, respectively. The multiple heat source case and the groundwater 
case had a similar $\mathrm{SCOP}_{\text {Sys. }}$. The system performance of the air case decreased to 2.62. The $\mathrm{SCOP}_{\text {sys }}$ of the seawater case dropped significantly by $33 \%$, because of the minimum seawater temperature at the evaporator outlet of $-1{ }^{\circ} \mathrm{C}$, which limited the extractable heat flow rate during the winter. Therefore, the electric peak load boiler capacity had to be $60 \%$ of the peak demand in order to obtain a feasible solution. In addition, the electric peak load boiler had to be in operation for $679 \mathrm{FLH}$ causing the SCOPsys to decrease so much, which would be equivalent to $2037 \mathrm{FLH}$, when compared to the initial capacity. A different design volume flow rate could have been used for seawater in cold climates.

\subsubsection{Change of temperature glide of heat source and total HP capacity}

The design volume flow rate of seawater increased by $68 \%$ to $1856 \mathrm{~m}^{3} / \mathrm{h}$ for a temperature glide of $3 \mathrm{~K}$ compared to using a glide of $5 \mathrm{~K}$. The changes in $\mathrm{SCOP}_{\text {sys }}$ and heat supply by the electric peak load boiler of the seawater case are presented in Fig. 9, together with the results of varying total HP capacity.

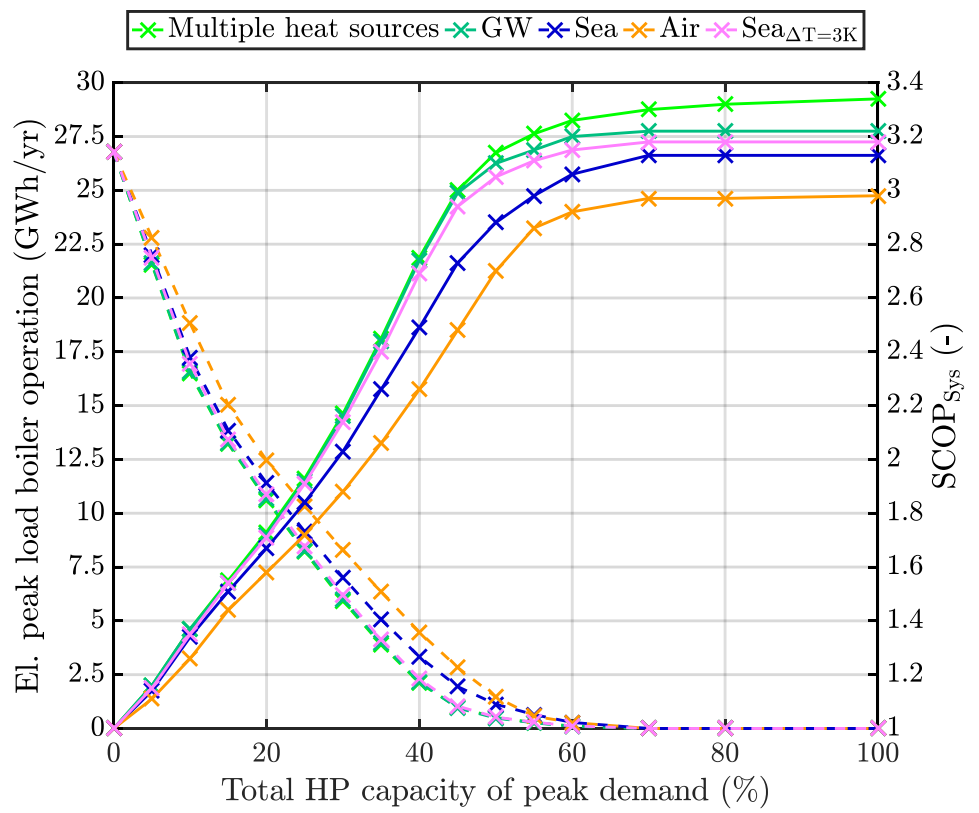

Fig. 9. Heat supply of electric peak load boiler (dashed) and SCOPsys (solid) as a function of total HP capacity

The change in temperature glide did not influence the multiple heat source case considerably, because the seawater HP was operated in only few hours during periods, in which the extractable heat flow rate was limited, as shown in Fig. A. 1.

The effects of varying the installed total HP capacity are shown in Fig. 9 in terms of SCOP Sys $_{\text {s }}$ and supplied heat of the electric peak load boiler over the year, since the capacity of the electric peak load boiler changed according to the installed total HP capacity. The heat supply by the electric peak load boiler increased for smaller total HP capacity. The air case and the seawater case required the largest amount of heat supplied by the electric peak load boiler compared to the multiple heat source case and the groundwater case. The supplied heat increases at

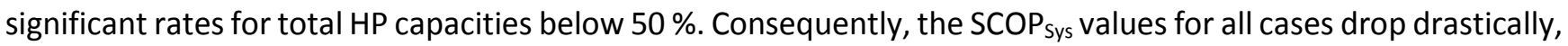
because the COP of the electric peak load boiler is 1 . Therefore, also the COSP Sys $_{\text {equals }} 1$ for all cases if all heat was supplied by the electric peak load boiler resulting in $26,790 \mathrm{TWh} / \mathrm{a}$.

The $\mathrm{SCOP}_{\text {sys }}$ values of the reference cases approached their maxima once the total HP capacity is $70 \%$ of the hourly peak demand. The SCOP sys already stabilised for total HP capacities above $60 \%$, which could be seen as a 
minimum design criteria to achieve high performance. The multiple heat source case improved its performance even further for larger total HP capacity, because the different heat sources can be used to a higher degree during the periods when they are the most beneficial.

The case of using seawater as heat source with a temperature glide of $3 \mathrm{~K}$ resulted in an improved SCOP sys $_{\text {close }}$ to the one of the groundwater case, because the electric peak load boiler was not required during periods, in which the extractable heat flow rate was otherwise limited. This result indicates that an economic optimum exists between an increase in performance and larger components required for the increased design volume flow rate.

\subsubsection{Change of storage capacity and Lorenz efficiency}

The reduction in storage capacity lowered the $\mathrm{SCOP}_{\text {sys }}$ of the systems, but not considerably for a total HP capacity of $80 \%$ of the hourly maximum peak demand. Changing the Lorenz efficiency by $\pm 20 \%$, affected the SCOP Sys $_{\text {of }}$ all four different cases in the same way. The performance differences between the cases remained the same.

\section{Discussion}

The results of hourly COPs of HPs using seawater or air show that they vary considerably during the year. Assuming a simple mean COP during the year will not predict the actual performance unless the expected heat demand and changes in ambient conditions are taken into account. Thereby, an accurate mean value could be determined, which was lower than the arithmetic mean that was used e.g. in [13].

Seasonal changes in COP of HPs integrated into the DH network of Copenhagen using seawater, sewage water or drinking water were analysed by Bach et al. [32]. Their calculated COPs of the seawater HPs follow a similar trend throughout the year as the ones calculated in the present study. They stated that the overall changes in COPs do not influence the results of monthly heat production much compared to a scenario assuming constant COPs, because the changes in COPs are small. However, the difference between their calculated minimum and maximum COPs for seawater HPs is smaller than the one calculated for this study, which may be explained by their use of a two-stage compression HP model using ammonia as refrigerant to calculate COPs, differences in $\mathrm{DH}$ forward and return temperatures as well as in seawater temperatures. They further discussed that calculation of hourly COPs may be relevant for air HPs, which was shown in the present work.

The presented results were based on typical weather conditions for Copenhagen and residential buildings complying with the Danish Building Standard 2015 [53]. The outcome varied if applied to warmer or colder regions, or if other types of buildings, such as near-future low-energy buildings, were considered. Consequently, the benefit of combining the use of different heat sources within one energy system may become more significant in the future.

The arithmetic mean $\mathrm{COP}_{\text {avg }}$ as the decision criterion may result in the wrong choice of heat source. This was shown by the comparison of $\mathrm{COP}_{\text {avg }}$ and $\mathrm{SCOP}_{\mathrm{HP}}$, as presented in Table 5. For the $\mathrm{COP}_{\text {avg, }}$ the order of highest performance was: seawater, air and then groundwater. This order differed for the $\mathrm{SCOP}_{\mathrm{HP}}$ as groundwater became the most efficient heat source to use and air the least efficient one. This is why a careful selection must be made depending on the expected heat demand in order to identify the most suitable heat source.

Lund and Persson [27] showed that the geographical availability of groundwater to DH networks and to the total heat demand in Denmark is the largest compared to seven other potential low-temperature heat sources. They did not state the share of the $\mathrm{DH}$ demand covered by the individual heat sources. This has been answered by the present study showing that groundwater was the most efficient heat source and covered the highest share of the heat demand.

The results show that calculating the COPs of HPs on hourly basis is required, if a number of different heat sources is used in an energy system. One heat source was preferred over others, but this changed during the year in 
order to always choose the heat source that resulted in highest SCOPsys. Changing the prioritization of heat sources will not be possible, if a fixed COP during the entire year is assumed. Therefore, the SCOP sys $_{\text {will result in }}$ a lower value. A need for different heat sources is very likely to happen in the Greater Copenhagen area, if a HP capacity of $300 \mathrm{MW}$ should be met by 2035 [31]. Capacity limitations of heat sources and local constraints of exploiting them may limit the availability and usage of only one heat source. Future energy systems based on large-scale HPs may consist of decentralised units using different heat sources. Therefore, it is important to identify how to plan and operate such units.

It was shown in Fig. 7 and Fig. A. 1 that for the multiple heat source case, the seawater HP was not in operation for two months from mid-March and that the groundwater HP was not in operation for five months from midMay until mid-October. This indicates that these heat sources could be used to provide free cooling if this was required and a district cooling network in place. In the same time, the district cooling network could be used as another heat source for a HP that provides heating and cooling at the same time. The optimal integration of heat sources could be determined by an optimization including district cooling as an additional heat source and available cooling capacity of groundwater and seawater depending on the operation of the HPs. A system supplying both heating and cooling requirements is also called a district heating and cooling system, as presented in e.g. [59], and it is very likely that such systems will be used more in the future considering increased cooling demands and comfort.

An assumption of the model was that the COP was independent of the HP load and operating conditions. Accounting for the dependency of the COP on the load or calculating the COP based on a detailed HP model could overcome the problem. However, the intension was to apply the developed model for energy planning purposes to any location with expected heat demand and temperatures of heat source and heat sink and not to restrict the results by a certain HP configuration or refrigerant. This was preferred over a detailed HP model, which design might change from case to case. In addition, the possible benefit of part load behaviour depends on the installed capacity of the HP unit. Large-scale HPs based on natural refrigerants, which are used in e.g. Denmark [60], are limited by a maximum capacity of e.g. $8 \mathrm{MW}$ [61]. Consequently, such HPs were installed in parallel or in series $[60,62]$. A HP model may be used after a new development region has been evaluated based on the current model, which can identify the most suitable heat sources and the required HP capacities.

No pressure losses nor auxiliary electricity consumption for pumps or fans were included. This would decrease the performance and may differ for heat sources resulting in a different prioritization.

A constant temperature glide of $5 \mathrm{~K}$ between inlet and outlet of heat source was assumed. This limited the extractable heat flow rate of heat sources during summer when a larger temperature glide may be available. This was accepted since the highest heat demand occurred in winter and the air source HPs were large enough to cover the DHW demands in summer.

Short-term storage was modelled to store a certain amount of heat in form of useful energy. Heat loss was assumed not to influence the temperature significantly. In reality, accumulator tanks are normally used to store heat for short periods. The water temperature in such storage tanks is usually stratified and heat loss would result in reduced temperatures. This effect will, however, be minor from a system perspective.

Other heat sources such as solar energy, geothermal energy or industrial waste heat as well as capacity limitations and cooling requirements were not analysed. Including these could lead to a higher system performance and could give an indication about the most advantageous heat sources out of an even wider range. Heat sources and heat sinks could complement each other, also when some are limited in capacity, to still satisfy a larger heating and cooling requirement efficiently.

Analysis of investment costs was omitted. This should be included in the model for life time cost calculations, which are crucial for decisions on whether or not to invest in a system based on a combination of heat sources or on one single heat source. 
If a few more of the listed limitations are addressed in the model, it could be used as a valuable assessment tool at an early energy planning stage to identify which heat sources or combinations of those might be best suitable for a certain area in terms of performance and economics. Such a system could be more efficient than HP solutions we are looking at today and could lead to a higher market penetration of large-scale HPs.

\section{Conclusion}

In the present study, the heat sources: groundwater, seawater and air were evaluated when used by HPs to supply heat to a DH network. A multiple heat source case combining the different heat sources with each other was analysed in detail and compared to three reference cases using the heat sources individually. The analysis was performed in the context of a case study for a large urban development district in Copenhagen. The investigated system was composed of HPs, an electric peak load boiler and short-term storage. Linear programming was used to optimize the seasonal performance of the system on an hourly basis.

The results show that the COP of seawater and air HPs varied greatly during the year. Inclusion of the heat demand determined the SCOP of HPs and helped to determine the solution with the highest overall system performance. It was shown that the SCOP of the seawater and air HPs, when considering heat demands, was $11 \%$ and $15 \%$ lower than the arithmetic mean COP. Using groundwater as a heat source the difference was only $3 \%$. This shows the importance of including variations in heat demand and source temperatures when planning HPs using heat sources with fluctuating profiles. In addition, it was shown that seawater as a heat source was limited by the minimum outlet temperature allowed.

The results show further that a maximum system performance may be achieved for HPs based on a combination of different heat sources, compared to using only one heat source. In this way, the heat source resulting in highest performance for each period was preferred to use. Groundwater was the prioritized heat source during winter, air the one in late-spring and summer, seawater the one during colder summer days and autumn.

A HP of same total capacity as the multiple heat source case using either groundwater, seawater or air would result in a reduction in system performance by $3 \%, 6 \%$ and $11 \%$, respectively.

It was further shown in the sensitivity analysis that the system performance depended on the proportion of the different heat sources, the climate region, total installed HP capacity and which building type was supplied. Especially, in the future it is expected that the potential benefit of combining different heat sources within one energy system may increase. A total HP capacity of at least $60 \%$ of the maximum hourly peak demand was recommended to achieve high system performance. If a combination of heat sources shall be considered, the groundwater HP capacity should be within $50 \%$ to $80 \%$ of the total HP capacity.

\section{Acknowledgements}

This research project was funded by EUDP (Energy Technology Development and Demonstration). Project title: "EnergyLab Nordhavn - New Urban Energy Infrastructures", project number: 64014-0555.

\section{References}

[1] Dansk Fjernvarme. Danish District Heating Association 2017. http://www.danskfjernvarme.dk/english/about-us (accessed August 28, 2017)

[2] The Danish Ministry of Climate and Energy. Energy Strategy 2050 - from coal, oil and gas to green energy (Danish) 2011. http://www.stm.dk/multimedia/Energistrategi_2050.pdf (accessed September 28, 2017)

[3] Dansk Fjernvarme. Statistik 2013/2014 Benchmarking 2014 2014. http://www.danskfjernvarme.dk/videnom/aarsstatistik/benchmarking-statistik-2013-2014 (accessed August 28, 2017)

[4] Lund H, Werner S, Wiltshire R, Svendsen S, Thorsen JE, Hvelplund F, et al. 4th Generation District Heating (4GDH). Integrating smart thermal grids into future sustainable energy systems. Energy 2014;68:1-11. doi:10.1016/j.energy.2014.02.089

[5] Ommen T, Elmegaard B. Exergetic evaluation of heat pump booster configurations in a low temperature district heating network. Proc ECOS 2012:1-14

[6] Elmegaard B, Ommen TS, Markussen M, Iversen J. Integration of space heating and hot water supply in low temperature 
district heating. Energy Build 2014. doi:10.1016/j.enbuild.2015.09.003

[7] Lund R, Østergaard DS, Yang X, Mathiesen BV. Comparison of Low-temperature District Heating Concepts in a Long-Term Energy System Perspective. Int J Sustain Energy Plan Manag 2017;12:5-18. doi:10.5278/ijsepm.2017.12.2

[8] Lund H, Mathiesen BV, Connolly D, Østergaard PA. Renewable energy systems - A smart energy systems approach to the choice and modelling of $100 \%$ renewable solutions. Chem Eng Trans 2014;39:1-6. doi:10.3303/CET1439001

[9] Connolly D, Lund H, Mathiesen, Brian Vad Østergaard, Poul Alberg M $\varnothing$ ller B, Nielsen S, Skov IR, Hvelplund FK, et al. Smart Energy Systems: Holistic and Integrated Energy Systems for the era of 100\% Renewable Energy 2013

[10] Lund R, Ilic DD, Trygg L. Socioeconomic potential for introducing large-scale heat pumps in district heating in Denmark. J Clean Prod 2016;139:219-29. doi:10.1016/j.jclepro.2016.07.135

[11] Department of Development and Planning AU. EnergyPLAN. http://www.energyplan.eu/ (accessed January 26, 2018)

[12] Henning D a G. MODEST-An energy-system optimisation model applicable to local utilities and countries. Energy 1997;22:1135-50. doi:10.1016/S0360-5442(97)00052-2

[13] Hedegaard K, Balyk O. Energy system investment model incorporating heat pumps with thermal storage in buildings and buffer tanks. Energy 2013;63:356-65. doi:10.1016/j.energy.2013.09.061

[14] Rinne S, Syri S. Heat pumps versus combined heat and power production as $\mathrm{CO} 2$ reduction measures in Finland. Energy 2013;57:308-18. doi:10.1016/j.energy.2013.05.033

[15] Nord N, Schmidt D, Kallert AMD. Necessary Measures to Include more Distributed Renewable Energy Sources into District Heating System. Energy Procedia 2017;116:48-57. doi:10.1016/j.egypro.2017.05.054

[16] Quiquerez L, Lachal B, Monnard M, Faessler J. The role of district heating in achieving sustainable cities: Comparative analysis of different heat scenarios for Geneva. Energy Procedia 2017;116:78-90. doi:10.1016/j.egypro.2017.05.057

[17] Dawoud B, Amer E, Gross D. Influence of massive heat-pump introduction on the electricity- generation mix and the GHG effect - Belgian case study. Int J Energy Res 2007;32:57-67. doi:10.1002/er.1366

[18] Kiviluoma J, Meibom P. Flexibility from district heating to decrease wind power integration costs. 12th Int Symp Dist Heat Cool 5-7th Sep 2010, Tallinn, Est 2010

[19] Connolly D, Mathiesen BV. A technical and economic analysis of one potential pathway to a $100 \%$ renewable energy system. Int J Sustain Energy Plan Manag 2014;1:7-28. doi:10.5278/ijsepm.2014.1.2

[20] Blarke MB, Lund H. Large-scale heat pumps in sustainable energy systems: System and project perspectives. Therm Sci 2007;11:143-52. doi:10.2298/TSCI0703143B

[21] Mathiesen BV, Lund H. Comparative analyses of seven technologies to facilitate the integration of fluctuating renewable energy sources. IET Renew Power Gener 2009;3:190-204. doi:10.1049/iet-rpg:20080049

[22] Østergaard PA, Andersen AN. Booster heat pumps and central heat pumps in district heating. Appl Energy 2016. doi:10.1016/j.apenergy.2016.02.144

[23] EMD International A/S. energyPRO. https://www.emd.dk/energypro/\# (accessed January 31, 2018)

[24] Holmgren K. Role of a district-heating network as a user of waste-heat supply from various sources - the case of Göteborg. Appl Energy 2006;83:1351-67. doi:10.1016/j.apenergy.2006.02.001

[25] Berntsson T. Heat sources - Technology, economy and environment. Int J Refrig 2002;25:428-38. doi:10.1016/S01407007(01)00034-2

[26] David A, Mathiesen BV, Averfalk H, Werner S, Lund H. Heat Roadmap Europe: Large-Scale Electric Heat Pumps in District Heating Systems. Energies 2017;10:578. doi:10.3390/en10040578

[27] Lund R, Persson U. Mapping of potential heat sources for heat pumps for district heating in Denmark. Energy $2015 ; 46$. doi:10.1016/j.energy.2015.12.127

[28] CPH City and Port Development. CPH 2025 Climate Plan 2012. http://kk.sites.itera.dk/apps/kk_pub2/index.asp?mode=detalje\&id=983 (accessed October 20, 2017)

[29] HOFOR. District Heating in Copenhagen: Energy-efficient, Low-carbon, and Cost-effective 2016. http://www.hofor.dk/wpcontent/uploads/2016/09/district_heating_in_cph.pdf (accessed August 24, 2017)

[30] Danish Board of District Heating. Copenhagen's district heating is now 53 percent CO2 neutral 2015. http://dbdh.dk/copenhagens-district-heating-is-now-53-percent-co2-neutral/ (accessed March 28, 2017)

[31] CTR, HOFOR, VEKS. Heat Planning for the Greater Copenhagen area (Danish) 2014. http://www.varmeplanhovedstaden.dk/ (accessed May 3, 2017)

[32] Bach B, Werling J, Ommen T, Münster M, Morales JM, Elmegaard B. Integration of large-scale heat pumps in the district heating systems of Greater Copenhagen. Energy 2016;107:321-34. doi:10.1016/j.energy.2016.04.029

[33] The Balmorel Open Source Project. Balmorel. http://www.balmorel.com/ (accessed January 23, 2017)

[34] GAMS Development Corp. GAMS. https://www.gams.com/ (accessed August 6, 2017)

[35] HOFOR. Fjernvarmeforsyning af Nordhavn (English: District heating supply of Nordhavn) 2013. https://www.kk.dk/indhold/borgerrepraesentationens-modemateriale/06022014/edoc-agenda/e19fb5ee-414c-44a9-b31f779c04262eb2/579ae4f0-63b3-486b-abe2-b70b02f25c0b 
[36] Granryd E, Ekroth I, Lundquist P, Melinder Å, Palm B, Rohlin P. Refrigerating Engineering. Department of Energy Technology Division of Applied Thermodynamics and Refrigeration Royal Institute of Technology, KTH; 2009

[37] Ommen TS, Elmegaard B, Markussen WB. Heat Pumps in CHP Systems: High-efficiency Energy System Utilising Combined Heat and Power and Heat Pumps. DTU Mechanical Engineering (DCAMM Special Report; No. S187), 2015

[38] Danish Energy Agency. Drejebog til store varmepumpeprojekter i fjernvarmesystemet (English: Guide for large-scale heat pump projects in district heating systems) 2014. https://ens.dk/sites/ens.dk/files/varme/drejebog_1.pdf (accessed February 1, 2017)

[39] F-Chart Software. Engineering Equation Solver. http://www.fchart.com/ees/ (accessed February 13, 2017)

[40] Brown WS. Physical properties of seawater. Springer Handb. Ocean Eng., 2016, p. 101-9. doi:10.1007/978-3-319-16649-0_5

[41] Danish Meteorological Institute (DMI). Modelled hydrographic conditions across $\emptyset$ resund/Kongedybet. 2017

[42] Ayub Z. World's Largest Ammonia Heat Pump (14 MWh) for District Heating in Norway-A Case Study. Heat Transf Eng 2016. doi:10.1080/01457632.2015.1052716

[43] Friotherm AG. Värtan Ropsten - The largest sea water heat pump facility worldwide, with 6 Unitop ${ }^{\circledR} 50 \mathrm{FY}$ and $180 \mathrm{MW}$ total capacity. http://www.friotherm.com/webautor-data/41/vaertan_e008_uk.pdf

[44] Ministry of Environment and Food of Denmark. The Danish Environmental Protection Agency. http://eng.mst.dk/ (accessed January 15, 2018)

[45] The MathWorks Inc. MATLAB Release 2016a. https://se.mathworks.com/ (accessed February 20, 2017)

[46] Grunnet Wang, P., Scharling, M., Pagh Nielsen, K., Kern-Hansen, C., \& Wittchen KB. 2001 - 2010 Danish Design Reference Year: Reference Climate Dataset for Technical Dimensioning in Building, Construction and other Sectors. Danmarks Meteorologiske Institut (DMI Technical Report; No. 13-19), 2013

[47] Danish Standards Foundation. DS 469:2013 Heating- and cooling systems in buildings (Danish). 2. 2013

[48] Jensen JK, Ommen T, Markussen WB, Elmegaard B. Design of serially connected ammonia-water hybrid absorptioncompression heat pumps for district heating with the utilisation of a geothermal heat source. Energy 2017;137:865-77. doi:10.1016/j.energy.2017.03.164

[49] Energylab Nordhavn. EnergyLab Nordhavn: New Urban Energy Infrastructures and Smart Components 2016. http://www.energylabnordhavn.com/about.html (accessed September 20, 2017)

[50] CPH City and Port Development. Nordhavnen - from idea to project 2012. http://www.nordhavnen.dk/ /media/_newnordhavnen/arhusgade_170912_low.pdf (accessed September 20, 2017)

[51] CPH City and Port Development. Personal communication with Peter Larsson 2017

[52] HOFOR. Personal communication. Building consumption data for 2017. 2018

[53] The Danish Transport and Construction Agency. The Building Regulations 2015 - bek. 1601 14/12/2015 2015. http://bygningsreglementet.dk/file/591081/br15_english.pdf (accessed September 19, 2017)

[54] Foteinaki K, Heller A, Rode C. Modeling energy flexibility of low energy buildings utilizing thermal mass. IAQVEC 2016, 9th Int Conf Indoor Air Qual Vent Energy Conserv Build 2016

[55] EQUA Simulation AB. IDA Indoor Climate and Energy. http://www.equa.se/en/ida-ice (accessed February 20, 2017)

[56] Danish Standards Foundation. Heating systems in buildings - Method for calculation of system energy requirements and system efficiencies - Part 3-1: Domestic hot water systems, characterisation of needs (tapping requirements). 2007

[57] Frederiksen S, Werner S. District heating and cooling. Studentlitteratur AB; 2013

[58] Thomas S, Suerkemper F, Adisorn T, Hauptstock D, Sparenberg CS-, Tholen L, et al. Energy Efficiency Policies in Europe - Case Study: Danish Building Code - Denmark. 2015

[59] Li Y, Rezgui Y, Zhu H. District heating and cooling optimization and enhancement - Towards integration of renewables, storage and smart grid. Renew Sustain Energy Rev 2017;72:281-94. doi:10.1016/j.rser.2017.01.061

[60] Danish Energy Agency. Inspirationskatalog for store varmepumpeprojekter i fjernvarmesystemet (English: Inspiration catalogue for large-scale heat pump projects in district heating 2017.

https://ens.dk/sites/ens.dk/files/Varme/inspirationskatalog_for_store_varmepumper.pdf

[61] Star Renewable Energy. High efficiency, Natural working fluid Heat Pumps. http://www.neatpumps.com/ (accessed January 31, 2018)

[62] Hoffmann K, Pearson DF. Ammonia Heat Pumps for District Heating in Norway - a case study. Inst Refrig 2011:1-8 


\section{Appendix A Annual operation of multiple heat source case}

The operation of the HPs for the multiple heat source case for the entire year is shown in Fig. A. 1. Comparing Fig. A. 1 and Fig. 6, it may be seen that the operation of HPs was prioritised based on COP.

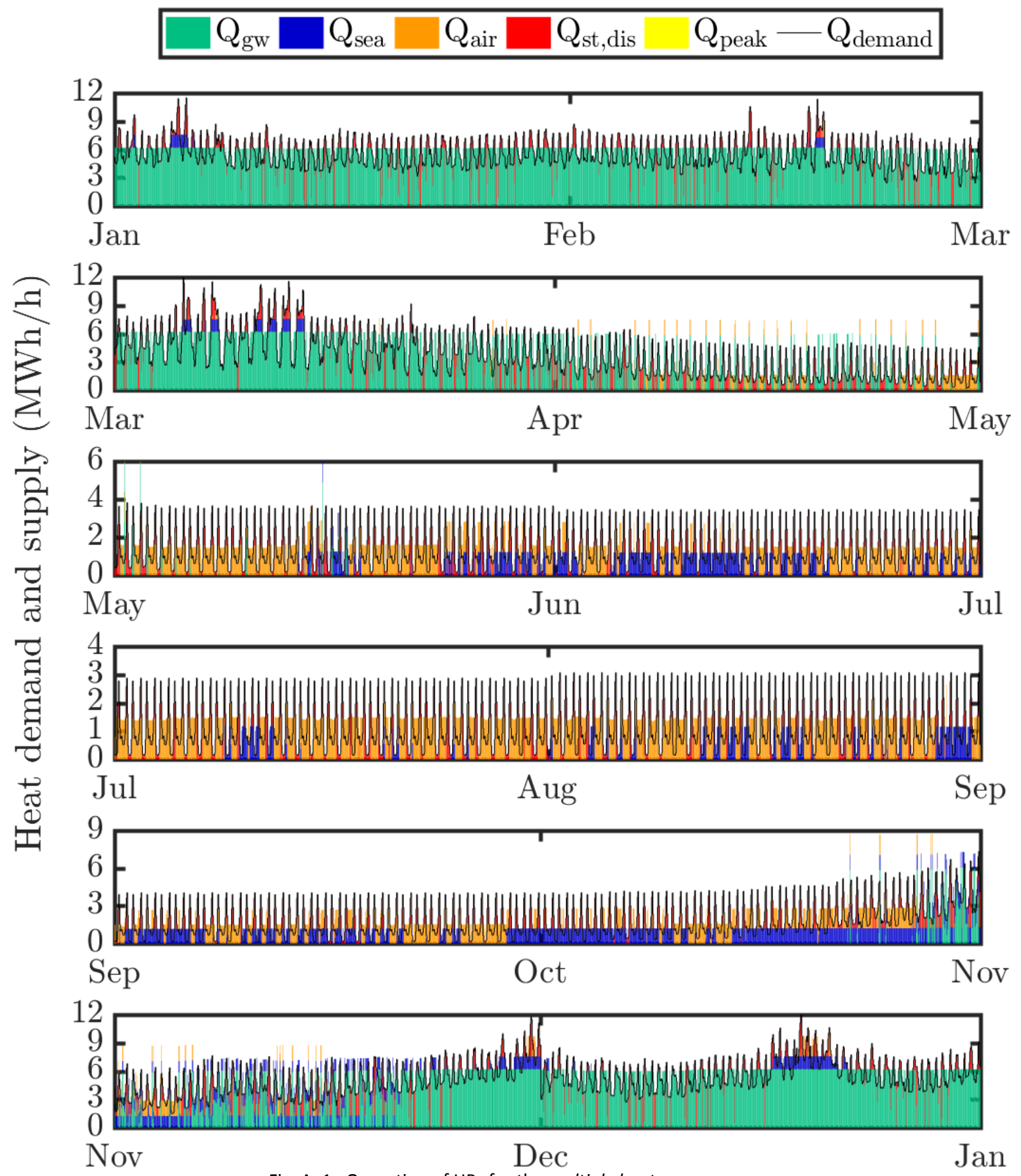

Fig. A. 1. Operation of HPs for the multiple heat source case 